\title{
Healthcare recommendations for Joubert syndrome
}

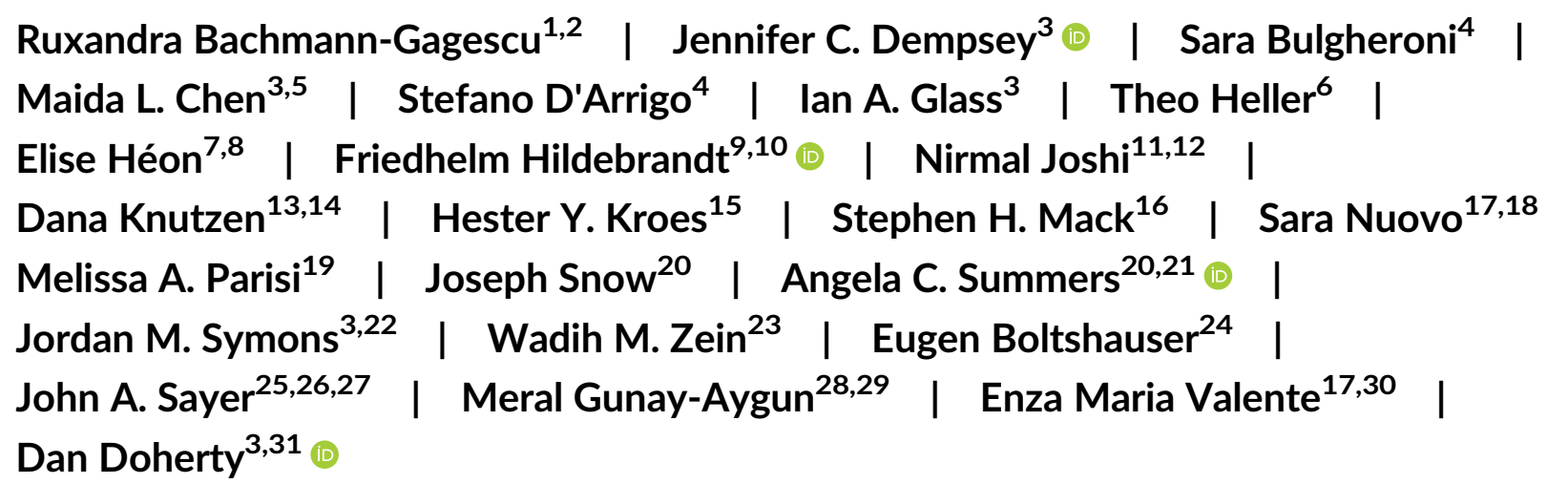

${ }^{1}$ Institute of Molecular Life Sciences, University of Zurich, Zurich, Switzerland

${ }^{2}$ Institute of Medical Genetics, University of Zurich, Schlieren, Switzerland

${ }^{3}$ Department of Pediatrics, University of Washington School of Medicine, Seattle, Washington

${ }^{4}$ Developmental Neurology Division, Fondazione IRCCS Istituto Neurologico Carlo Besta, Milan, Italy

${ }^{5}$ Division of Pulmonary and Sleep Medicine, Seattle Children's Hospital, Seattle, Washington

${ }^{6}$ Liver Diseases Branch, National Institute of Diabetes and Digestive and Kidney Diseases, National Institutes of Health, Bethesda, Maryland

${ }^{7}$ Department of Surgery, Hospital for Sick Children, Toronto, Ontario, Canada

${ }^{8}$ Department of Ophthalmology and Vision Science, University of Toronto, Toronto, Ontario, Canada

${ }^{9}$ Department of Pediatrics, Harvard Medical School, Boston, Massachusetts

${ }^{10}$ Division of Nephrology, Boston Children's Hospital, Boston, Massachusetts

${ }^{11}$ Department of Anesthesia, Deaconess Hospital, Evansville, Indiana

${ }^{12}$ Anesthesia Dynamics, LLC, Evansville, Indiana

${ }^{13}$ Department of Obstetrics and Gynecology, Baylor College of Medicine, Houston, Texas

${ }^{14}$ The Children's Hospital of San Antonio, San Antonio, Texas

${ }^{15}$ Department of Medical Genetics, University Medical Center Utrecht, Utrecht, The Netherlands

${ }^{16}$ Joubert Syndrome and Related Disorders Foundation, Petaluma, California

${ }^{17}$ Neurogenetics Lab, IRCCS Santa Lucia Foundation, Rome, Italy

${ }^{18}$ Department of Medicine and Surgery, University of Salerno, Salerno, Italy

${ }^{19}$ Intellectual and Developmental Disabilities Branch, Eunice Kennedy Shriver National Institute of Child Health and Human Development, National Institutes of Health, Bethesda, Maryland

${ }^{20}$ Office of the Clinical Director, National Institute of Mental Health, National Institutes of Health, Bethesda, Maryland

${ }^{21}$ Department of Psychology, Fordham University, Bronx, New York

${ }^{22}$ Division of Nephrology, Seattle Children's Hospital, Seattle, Washington

${ }^{23}$ Ophthalmic Genetics and Visual Function Branch, National Eye Institute, National Institutes of Health, Bethesda, Maryland

${ }^{24}$ Department of Pediatric Neurology (emeritus), Children's University Hospital, Zürich, Switzerland

${ }^{25}$ Institute of Genetic Medicine, Newcastle University, Newcastle upon Tyne, UK

${ }^{26}$ Renal Services, Newcastle upon Tyne Hospitals NHS Foundation Trust, Newcastle upon Tyne, UK

${ }^{27} \mathrm{NIHR}$ Newcastle Biomedical Research Centre, Newcastle upon Tyne, UK

${ }^{28}$ Medical Genetics Branch, National Human Genome Research Institute, National Institutes of Health, Bethesda, Maryland

${ }^{29}$ Department of Pediatrics and McKusick-Nathans Institute of Genetic Medicine, Johns Hopkins University School of Medicine, Baltimore, Maryland 


\footnotetext{
${ }^{30}$ Department of Molecular Medicine, University of Pavia, Pavia, Italy

${ }^{31}$ Center for Integrative Brain Research, Seattle Children's Research Institute, Seattle, Washington
}

\section{Correspondence}

Dan Doherty, University of Washington, 1959 NE Pacific St., RR247, Box 356320 Seattle, WA 98195.

Email: ddoher@uw.edu

\section{Funding information}

European Research Council; Fondazione

Pierfranco e Luisa Mariani; Italian Ministry of Health; Kidney Research UK; Medical Research Council; National Institute of Child Health and Human Development, Grant/Award Number: U54HD083091 sub-project 6849; National Institute of Neurological Disorders and Stroke, Grant/Award Number: R01NS064077; National Institutes of Health, Grant/Award Number: 068306; NIH Intramural Research Program; Northern Counties Kidney Research Fund

\begin{abstract}
Joubert syndrome (JS) is a recessive neurodevelopmental disorder defined by a characteristic cerebellar and brainstem malformation recognizable on axial brain magnetic resonance imaging as the "Molar Tooth Sign". Although defined by the neurological features, JS is associated with clinical features affecting many other organ systems, particularly progressive involvement of the retina, kidney, and liver. JS is a rare condition; therefore, many affected individuals may not have easy access to subspecialty providers familiar with JS (e.g., geneticists, neurologists, developmental pediatricians, ophthalmologists, nephrologists, hepatologists, psychiatrists, therapists, and educators). Expert recommendations can enable practitioners of all types to provide quality care to individuals with JS and know when to refer for subspecialty care. This need will only increase as precision treatments targeting specific genetic causes of JS emerge. The goal of these recommendations is to provide a resource for general practitioners, subspecialists, and families to maximize the health of individuals with JS throughout the lifespan.

\section{KEYWORDS}

Joubert syndrome, ciliopathy, treatment, retina, kidney, liver

\section{$1 \mid$ INTRODUCTION}

Joubert syndrome (JS, MIM PS213300) is a recessive neurodevelopmental disorder defined by a characteristic cerebellar and brainstem malformation recognizable on axial brain magnetic resonance imaging (MRI) as the "Molar Tooth Sign" (MTS; Joubert, Eisenring, Robb, \& Andermann, 1969; Maria et al., 1997). This appearance results from a combination of abnormalities: cerebellar vermis aplasia/hypoplasia, thick and horizontally oriented superior cerebellar peduncles, and often, a deep interpeduncular fossa. Clinically, individuals with JS typically present as infants with hypotonia, abnormal eye movements, respiratory control disturbances, and as children or adults, ataxia and/or cognitive impairment (Doherty, 2009; Parisi \& Glass, 1993; Romani, Micalizzi, \& Valente, 2013). In addition to these core features, the majority of individuals with JS also have involvement of other body systems including the eye, kidney, liver, and skeleton (Bachmann-Gagescu et al., 2015). Therefore, rather than a purely neurological condition, JS is a multisystem disorder in which several of the additional features may be progressive, thereby substantially complicating medical management. While the diagnosis is often made initially in the setting of a neurology, genetics, or developmental pediatrics clinic, the frequent involvement of other organ systems means that monitoring for complications is required, with referral to the corresponding subspecialists when specific organ involvement is suspected. The purpose of this review is to provide management recommendations to minimize medical complications and maximize quality of life for individuals with JS. We hope to address a broad audience including families, primary care providers and subspecialists, since JS is rare, and few providers have experience with more than a handful of affected individuals.

Given that JS is rare (prevalence estimated at 1/55,000-1/200,000; Kroes, Fransen van de Putte, Ravesloot, \& Lindhout, 2007; Nuovo et al., in press; Parisi \& Glass, 1993), the present recommendations represent a consensus of expert opinion, based on observed outcomes in JS and extrapolation from more common disorders. In general, these recommendations focus on the goals of monitoring and treatment without being directive as to which medical specialists or techniques are most appropriate, since the availability of subspecialists and specific medical technologies varies widely. Some of the evaluations and treatments mentioned in these recommendations are not available in all healthcare settings, so we try to provide options that will work in a variety of healthcare environments.

JS is part of the larger group of disorders called ciliopathies, based on shared genetic causes and overlapping phenotypes related to dysfunction of the primary cilium (Reiter \& Leroux, 2017). Therefore, some of the present recommendations may be useful for individuals with other related ciliopathies, in particular nephronophthisis (MIM PS256100), Leber congenital amaurosis (MIM PS204000), SeniorLøken syndrome (MIM PS266900), acrocallosal syndrome (MIM 200990), oral-facial-digital syndromes (MIM PS311200), or MORM ("Mental retardation, truncal Obesity, Retinal dystrophy, and Micropenis") syndrome (MIM 610156). 


\section{2 | METHODS}

We reviewed the medical literature from the time of the initial description of JS (Joubert et al., 1969) to the present. The estimated prevalence of features is based on a cohort of $>600$ individuals with JS ("University of Washington (UW) cohort"; BachmannGagescu, Dempsey et al., 2015), an overlapping series of 100 individuals with JS evaluated through the intramural National Institutes of Health research protocol "Clinical and Molecular
Investigations Into Ciliopathies" (ClinicalTrials.gov, NCT00068224-"The NIH cohort"), and the literature. The NIH cohort appears enriched for liver involvement and coloboma compared to other cohorts; this may be due to differences in enrollment, assessment for clinical features, or other factors. No trials of monitoring strategies or treatments have been performed in individuals with JS; therefore, the recommendations below are based on professional judgment of the authors and extrapolation from paradigms for similar issues in other populations.
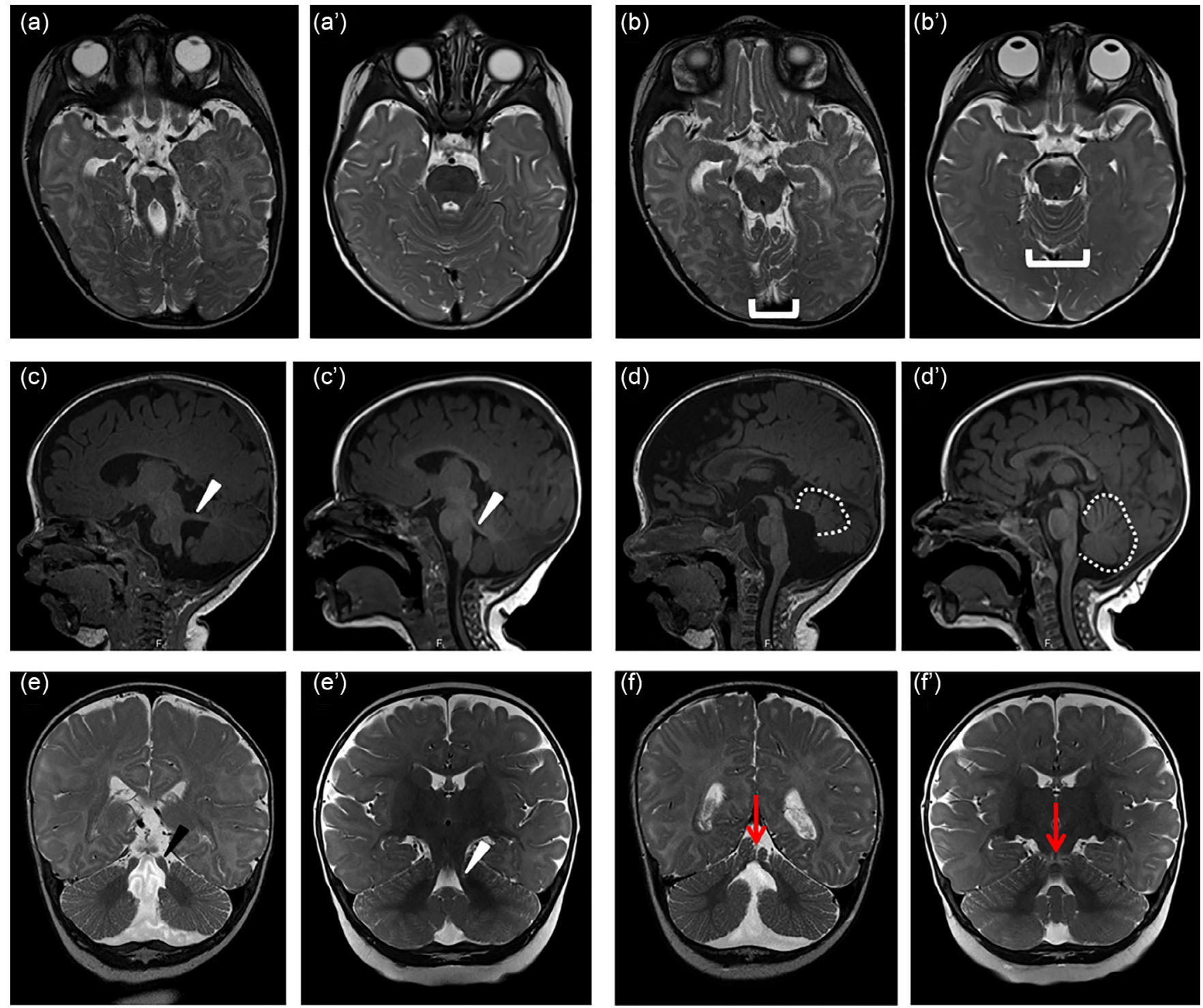

FIGURE 1 Diagnostic features of Joubert syndrome on magnetic resonance imaging (MRI). (a) molar tooth sign (MTS) on T2-weighted axial images due to the combination of long, thick superior cerebellar peduncles (the roots of the tooth) and a deep interpeduncular fossa (the cutting surface of the tooth). This appearance is not always captured in a single plane, so it is important to evaluate the MRI as a whole rather than relying on a single image. (b) Superior cerebellar foliar dysplasia (bracket) on axial T2-weighted images, sometimes seen in the absence of the MTS in individuals carrying pathogenic variants in the JS-associated genes (note that the folia at this level are usually shaped like a $U$ or V). (c) Horizontally oriented superior cerebellar peduncle (white arrowhead) on T1-weighted parasagittal image; (d) Vermis hypoplasia (outline), elevated roof of the fourth ventricle, and rostrally displaced fastigium on T1-weighted sagittal image; (e) Long, thick superior cerebellar peduncles (black arrowhead) T2-weighted coronal image; (f) Appearance of a cerebellar cleft (black arrow indicating fluid at the cerebellar midline) on T2-weighted coronal image. ( $\left.a^{\prime}-f^{\prime}\right)$ similar images from an unaffected individual of the same age 


\section{1 | Clinical diagnosis of JS: Diagnostic criteria}

For the purpose of this article, the diagnosis of JS requires the presence of the MTS on axial brain MRI (or computed tomography [CT]) of optimal quality, including thin sections through the posterior fossa (Figure 1a). Despite widespread publication of the imaging features of JS, the diagnosis is initially missed in a substantial number of individuals, so review by an experienced pediatric neuroradiologist, neurologist, or other practitioner with specific knowledge of JS can be critical. In some individuals, the features of the MTS are not captured in a single image and must be reconstructed from multiple images. Superior cerebellar dysplasia on axial view (Figure 1b), thick, horizontally oriented superior cerebellar peduncles (Figure 1c,e) and elevated roof of the fourth ventricle (Figure 1d) on sagittal views, as well as a cleft vermis on coronal view (Figure 1f) can also be helpful. Diffusion tensor imaging has been used to highlight deficient midline crossing (decussation) of the superior cerebellar peduncle tracts near the red nucleus, which appears to be present in the majority of individuals (Poretti et al., 2007; Widjaja, Blaser, \& Raybaud, 2006). Multiple additional brain anomalies have been described in individuals with JS as described in the Section 2.3.1 below.

Not surprisingly, individuals with a subtle MTS or without the full combination of imaging features that result in the MTS can still have pathogenic variants in genes associated with JS (unpublished observations and (Enokizono et al., 2017; Parisi et al., 2004; Shaheen et al., 2016)). The risk of retinal, kidney, and liver involvement in individuals with partial imaging features of JS is unknown.

In the absence of an appropriate brain MRI, a provisional diagnosis of JS can be made based on classic features of hypotonia, developmental delay, ataxia, ocular motor apraxia, and respiratory rhythm disturbances (tachypnea and/or apnea), along with cerebellar vermis hypoplasia by ultrasound or CT imaging. JS is not associated with an easily recognizable facial appearance; however, some distinctive facial features, such as a prominent lower jaw, are shared by many individuals and can be supportive of the diagnosis (Braddock, Henley, \& Maria, 2007; Maria, Boltshauser, Palmer, \& Tran, 1999).

Prenatally, the possibility of JS can be raised by cerebellar vermis hypoplasia detected on routine ultrasound. Fetal MRI may be helpful in further delineating anomalies identified by ultrasound (Aslan et al., 2002; Doherty et al., 2005; Fluss et al., 2006; Saleem \& Zaki, 2010); however, the typical MTS is often not detected prenatally (unpublished observations). In pregnant women with a prior affected child, the finding of definite vermis hypoplasia on ultrasound or MRI can be considered diagnostic. In the absence of a family history, the reliability of prenatal diagnosis by imaging is unknown; however, a combination of cerebellar vermis hypoplasia with other distinctive JS/ciliary features such as polydactyly, or enlarged, cystic, or echogenic kidneys may suggest a JS diagnosis even in the absence of a family history.

The differential diagnosis for JS includes other disorders with anomalies of the posterior fossa such as Dandy-Walker malformation, Poretti-Boltshauser syndrome (MIM 615960), and other conditions associated with ataxia and/or cerebellar vermis hypoplasia. Many children with JS are first given a diagnosis of ocular motor apraxia, or ataxic cerebral palsy before the MTS is identified. The differential diagnosis also includes genetically and phenotypically overlapping ciliopathies such as Meckel syndrome (MIM PS249000) which likely represents the severe end of a Joubert-Meckel spectrum, oralfacial-digital (MIM PS311200), acrocallosal (MIM200990), MainzerSaldino (MIM 266920), COACH (MIM 216360, Cerebellar vermis hypo/aplasia, Oligophrenia, Ataxia, ocular Coloboma, and Hepatic fibrosis), or hydrolethalus (MIM PS236680) syndromes. For the purpose of this review, we include all individuals with the MTS under the umbrella of JS, even if they have other clinical features consistent with other diagnostic categories. This includes diagnostic categories such as Joubert Syndrome and Related Disorders, cerebellorenal syndromes, as well as subtypes of JS defined by features outside the brain such as JS with renal involvement or JS with oralfacial-digital features (Brancati, Dallapiccola, \& Valente, 2010; Parisi \& Glass, 2003). In fact, only a minority of people with JS have isolated brain involvement. When individuals with JS have atypical clinical features (particularly in consanguineous families), the possibility of a second unrelated genetic disorder should be considered and additional genetic testing beyond known ciliopathy genes may be warranted.

\section{2 | Molecular diagnosis of JS}

JS can be caused by pathogenic variants in $>35$ genes (Table 1). Biallelic pathogenic variants (or hemizygous pathogenic OFD1 variants) in one of the known JS-associated genes can be identified in $50-92 \%$ of individuals with JS depending on the cohort, sequencing method and criteria for causal variants (Bachmann-Gagescu, Dempsey, et al., 2015; Shaheen et al., 2016; Vilboux and others, 2017). In two overlapping cohorts, 5-6 genes (AHI1, CC2D2A, CEP290, CPLANE1, KIAA0586, and TMEM67) account for $40-70 \%$ of families (Bachmann-Gagescu, Dempsey, et al., 2015; Vilboux and others, 2017). Given this substantial genetic heterogeneity (i.e., multiple genetic causes for the same phenotype), and the fact that no single variant or gene predominates, the most time-efficient and economical means of molecular diagnosis can be achieved through nextgeneration sequencing (NGS) of either a panel of known JS genes, an exome (protein coding regions), or a genome (all DNA that can be sequenced). These latter methods have the advantage of requiring no specific set-up or updating as additional genes are associated with the phenotype.

For several ethnic groups, initial sequencing for common founder variants may be logical. Specifically, the TMEM216 p.R73L variant is common in individuals of Ashkenazi origin and TMEM237 p.R18* is common in Hutterites (Edvardson et al., 2010; Huang et al., 2011). In French Canadians, several recurring CPLANE1, CC2D2A, and TMEM231 pathogenic variants have been identified, so genetic testing can be prioritized by ethnic background (Srour, Hamdan, et al., 2012; Srour, Schwartzentruber, et al., 2012); however, these associations 
are not sufficient to enable reliable prediction of the genetic cause based on the phenotypes, so sequencing of all JS-associated genes by NGS is often preferable.

The motivation underlying the identification of a molecular diagnosis, besides confirming the clinical diagnosis of JS and providing information regarding recurrence risk/family planning, lies in the known gene-phenotype correlations (Bachmann-Gagescu, Dempsey, et al., 2015; Brancati et al., 2007; Brancati et al., 2009; Doherty et al.,
2010; Vilboux and others, 2017). Indeed, these correlations can be used to adjust the frequency of monitoring for progressive features such as retinal dystrophy and kidney disease, as described in Tables 3 and 4 and the Section 2.5 below. Furthermore, it may be prudent to avoid nephrotoxic medications in individuals at the highest risk for kidney involvement, without unnecessarily restricting these medications in those at low risk. In the future, the genetic diagnosis may determine eligibility for specific therapies such as gene-specific

TA B LE 1 Genes associated with Joubert syndrome and risk of complications

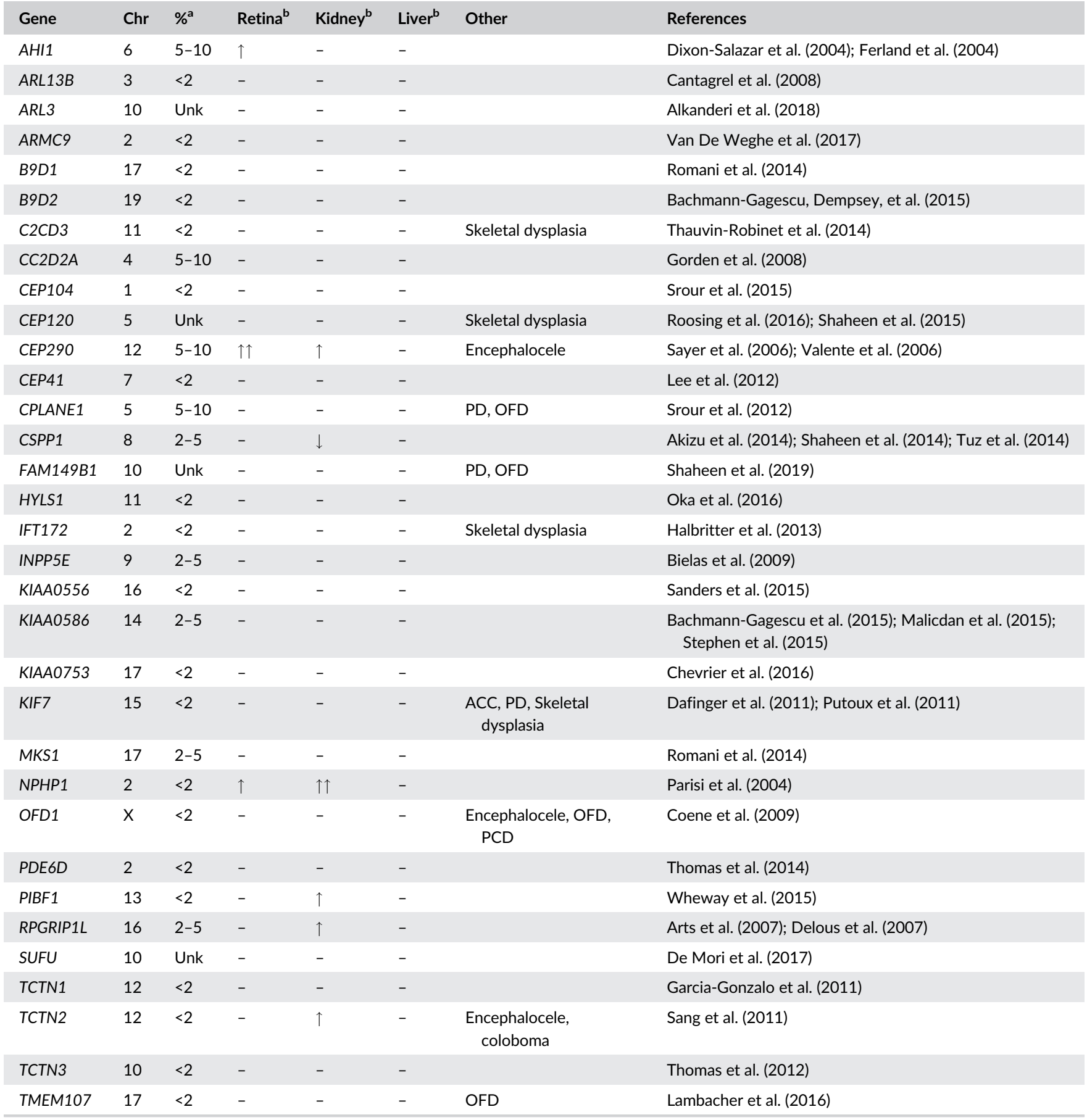


TABLE 1 (Continued)

\begin{tabular}{llllllll}
\hline Gene & Chr & $\%^{\mathbf{a}}$ & Retina $^{\mathbf{b}}$ & Kidney $^{\mathbf{b}}$ & Liver $^{\mathbf{b}}$ & Other $^{\text {Ot }}$ & References \\
\hline TMEM138 & 11 & $<2$ & - & - & - & Lee et al. (2012) \\
\hline TMEM216 & 11 & $2-5$ & - & - & - & Edvardson et al. (2010); Valente et al. (2010) \\
\hline TMEM231 & 16 & $<2$ & - & - & - & Srour et al. (2012) \\
\hline TMEM237 & 2 & $<2$ & - & - & - & & Huang et al. (2011) \\
\hline TMEM67 & 8 & $5-10$ & $\downarrow$ & $\uparrow$ & $\uparrow \uparrow$ & Coloboma, PD & Baala et al. (2007) \\
\hline
\end{tabular}

Note: The following genes are not listed due to lack of sufficient evidence that they are associated with JS (only one family, insufficient clinical information, and/or lack of biallelic variants): TTC21B (no biallelic variants in JS, variants reported in families with other ciliopathies; Davis et al., 2011), ZNF423 (one family with possible JS; Chaki et al., 2012), CLUAP1 (one family with JS; Johnston et al., 2017), EXOC8 (one family with JS; Dixon-Salazar et al., 2012), CELSR2 (one family in each of two papers, variants not reported for one family; Shaheen et al., 2016; Vilboux et al., 2017), POC1B (one family; Beck et al., 2014), CEP164 (one family with JS, variants reported in families with other ciliopathies; Chaki et al., 2012; Vilboux and others, 2017), INTU (insufficient imaging informaton in several patients with ciliopathy phenotypes; Bruel et al., 2017, 2018; Toriyama et al., 2016).

Abbreviations: ACC, agenesis of the corpus callosum; Chr, chromosome; OFD, oral facial digital features; PCD, primary ciliary dyskinesia; PD, polydactyly; Unk, unknown (not found in the UW cohort).

aBased on panel sequencing 572 families in the University of Washington cohort.

${ }^{\mathrm{b}} \uparrow$ weak positive association, $\uparrow \uparrow$ strong positive association, $\downarrow$ weak negative association, - no known statistical association (all studies to date are underpowered to identify small differences in risk associated with less frequent genetic causes). These features may have been reported in some individuals.

medications, antisense oligonucleotide treatments, or gene therapy (see Section 2.6 below).

\section{3 | System-by-system review of potential clinical issues}

\subsection{1 | Neurodevelopmental}

Essentially all individuals with JS experience hypotonia and motor delays during infancy and early childhood, usually evolving to ataxia as they get older. Abnormal eye movements and abnormal respiratory control are also seen in most, but may be subtle. Cognition is impaired in most, although a minority of individuals have IQs in the normal range (Bulgheroni et al., 2016; Fennell, Gitten, Dede, \& Maria, 1999; Gitten, Dede, Fennell, Quisling, \& Maria, 1998; Summers et al., 2017). In general, adaptive function correlates with cognitive function (Bulgheroni et al., 2016; Summers et al., 2017). However, slowed processing speed is common, so neuropsychological and school evaluations should examine both full scale intelligence quotient (FSIQ) and the generalized ability index (GAI) or similar measures to help contextualize the individual's intellectual abilities. Because the GAI relies less on speeded and motor tasks, a more accurate representation of cognitive abilities may be ascertained from this or similar scores than from a traditional measure of FSIQ. Developmental outcome studies must be interpreted with caution due to potential ascertainment biases (for more or less severely affected individuals) and difficulties measuring IQ in the presence of significant motor, communication, and visual impairments. Regardless, the range of neurodevelopmental outcome is very broad. Speech production is impacted out of proportion to language comprehension due to oral motor apraxia (Braddock, Farmer, Deidrick, Iverson, \& Maria, 2006). Periodic developmental monitoring is required, as well as standard therapies (physical, occupational, and speech/language) and educational interventions to build on areas of strength and target areas of weakness. No specific types of therapy have been shown to be more or less effective in this population. Motor issues, particularly the ataxia and the ocular motor apraxia, appear to improve as children mature. Most children with JS eventually walk independently, although a subset requires wheelchairs for some or all mobility.

Multiple additional brain anomalies have been described in individuals with JS (Bachmann-Gagescu, Dempsey, et al., 2015; Poretti et al., 2017), most commonly cerebellar hemisphere enlargement, malrotation of the hippocampi, ventriculomegaly, dysgenesis of the corpus callosum, polymicrogyria, heterotopia, and occipital encephalocele. While vermis size and abnormal EEG have been associated with severity of neurodevelopmental outcome (Poretti et al., 2017; Summers et al., 2017), no imaging or clinical features can reliably predict neurodevelopmental outcome in a given individual. It is suspected that additional major brain malformations, multiorgan involvement, chronic mechanical ventilation, and sensory impairments are associated with higher risk of more severely abnormal neurodevelopmental outcomes.

Ptosis, strabismus, and abnormal eye movements including nystagmus and ocular motor apraxia are neurologically based vision issues which may be present to some degree in all individuals (Brooks et al., 2018; Khan et al., 2008; Sturm et al., 2010; Weiss et al., 2009). In particular, ocular motor apraxia (head thrusting to shift gaze) is characteristic of JS, although it can be seen in other conditions. While visual acuity is often normal and eye movements tend to improve with time, abnormal smooth pursuit and saccades likely result in some degree of functional visual impairment, particularly when objects or the individual's head are moving.

Seizures have been described in a number of individuals with JS (minimum prevalence 10\%; Bachmann-Gagescu, Dempsey, et al., 2015) and must be specifically sought out during recording of the medical history. No single seizure type appears to dominate and there 
TAB LE 2 Prevalence, onset, and management of medical complications associated with Joubert syndrome

\begin{tabular}{|c|c|c|c|c|}
\hline & $\begin{array}{l}\text { Prevalence } \\
(\%)^{\mathrm{a}}\end{array}$ & Onset & $\begin{array}{l}\text { Specialized tests/referrals to } \\
\text { consider based on } \mathrm{Hx} / \mathrm{PE} / \text { routine } \\
\text { tests }\end{array}$ & Management/treatment \\
\hline MTS & 100 & Congenital & & \\
\hline Encephalocele & 8 & Congenital & MRI, Neurosurgery consultation & Surgery if clinically indicated \\
\hline Dystonic episodes & Rare & Unknown & Neurology consultation & $\begin{array}{l}\text { Behavioral (remove inciting factors), } \\
\text { medication trials, tooth removal } \\
\text { for severe biting }\end{array}$ \\
\hline Seizures & $>10$ & Unknown & EEG, Neurology consultation & Antiepileptic treatment as required \\
\hline $\begin{array}{l}\text { Ocular motor apraxia, } \\
\text { ophthalmoplegia }\end{array}$ & $\sim 80$ & Congenital & Ophthalmology consultation & $\begin{array}{l}\text { Supportive interventions for visual } \\
\text { impairment }\end{array}$ \\
\hline \multicolumn{5}{|l|}{ Behavior/psychiatric } \\
\hline $\begin{array}{l}\text { Self-injury, anxiety, } \\
\text { stereotypies, depression, } \\
\text { ADHD, hallucinations, sleep } \\
\text { disturbances }\end{array}$ & Unknown & $\begin{array}{l}\text { Early childhood } \\
\text { to adulthood }\end{array}$ & $\begin{array}{l}\text { Functional behavioral analysis, } \\
\text { developmental pediatrics or } \\
\text { psychiatry consultation, sleep } \\
\text { medicine evaluation }\end{array}$ & $\begin{array}{l}\text { Behavioral interventions, } \\
\text { medications }\end{array}$ \\
\hline Obstructive apnea & Unknown & $\begin{array}{l}\text { Neonatal to } \\
\text { adulthood }\end{array}$ & $\begin{array}{l}\text { Sleep medicine/pulmonology/ENT } \\
\text { consultation } \\
\text { polysomnography, echocardiogram }\end{array}$ & $\begin{array}{l}\text { Supplementary oxygen, } \mathrm{PAP}, \mathrm{T} / \mathrm{A} \text {, if } \\
\text { indicated }\end{array}$ \\
\hline $\begin{array}{l}\text { Restrictive lung disease } \\
\text { (w/skeletal dysplasia) }\end{array}$ & Rare & Congenital & $\begin{array}{l}\text { Chest X-ray } \\
\text { Pulmonology consultation }\end{array}$ & $\begin{array}{l}\text { Respiratory support if indicated, } \\
\text { thoracic expansion if indicated }\end{array}$ \\
\hline \multicolumn{5}{|l|}{ Ophthalmology } \\
\hline Strabismus & $>31$ & $\begin{array}{l}\text { Neonatal to } \\
\text { adolescence }\end{array}$ & $\begin{array}{l}\text { Cover-uncover test, Ophthalmology } \\
\text { consultation }\end{array}$ & $\begin{array}{l}\text { Spectacles, patching or pupillary } \\
\text { dilation, surgery with caution due } \\
\text { to underlying neurological } \\
\text { abnormality }\end{array}$ \\
\hline Ptosis & $>19$ & Congenital & Ophthalmology consultation & Surgery if indicated \\
\hline Retinal dystrophy & 30 & $\begin{array}{l}\text { Neonatal to } \\
\text { adulthood }\end{array}$ & $\begin{array}{l}\text { Ophthalmology consultation, } \\
\text { consider OCT, ERG, FAF if } \\
\text { indicated }\end{array}$ & $\begin{array}{l}\text { Supportive interventions for visual } \\
\text { impairment }\end{array}$ \\
\hline Coloboma & 17 & Congenital & Ophthalmology consultation & $\begin{array}{l}\text { Supportive interventions for visual } \\
\text { impairment }\end{array}$ \\
\hline \multicolumn{5}{|l|}{ Kidney } \\
\hline $\begin{array}{l}\text { Fibrocystic kidney disease/ } \\
\text { nephronophthisis/cystic } \\
\text { dysplasia }\end{array}$ & 25 & $\begin{array}{l}\text { Neonatal to } \\
\text { adulthood }\end{array}$ & $\begin{array}{l}\text { Nephrology consultation } \\
\text { bone density scan, } \\
\text { kidney biopsy }\end{array}$ & $\begin{array}{l}\text { Medications for support of } \\
\text { decreasing kidney function; } \\
\text { diagnosis and treatment of } \\
\text { hypertension, prevention of }\end{array}$ \\
\hline
\end{tabular}


TABLE 2 (Continued)

$\begin{array}{lll}\text { Prevalence } & & \begin{array}{l}\text { Specialized tests/referrals to } \\ \text { consider based on Hx/PE/routine }\end{array} \\ (\%)^{a} & \text { Onset } & \text { tests }\end{array}$

\section{Management/treatment}

dehydration in early disease and fluid overload in late disease; in case of ESKD: dialysis, kidney transplantation

\begin{tabular}{|c|c|c|c|c|}
\hline \multicolumn{5}{|l|}{ Liver } \\
\hline Congenital hepatic fibrosis & 14 & $\begin{array}{l}\text { Congenital to } \\
\text { adulthood }\end{array}$ & GI/hepatology consultation & $\begin{array}{l}\text { Medications for management of } \\
\text { portal hypertension ablation of } \\
\text { varices, porto-systemic shunting } \\
\text { if indicated, liver transplant }\end{array}$ \\
\hline \multicolumn{5}{|l|}{ Musculoskeletal } \\
\hline Polydactyly & 15 & Congenital & X-ray, orthopedics consultation & $\begin{array}{l}\text { Surgery if indicated for functional or } \\
\text { aesthetic reasons }\end{array}$ \\
\hline Scoliosis & $>5$ & $\begin{array}{l}\text { Childhood- } \\
\text { adulthood }\end{array}$ & X-ray, orthopedics consultation & $\begin{array}{l}\text { Surgery if indicated for respiratory } \\
\text { compromise or positioning (rare) }\end{array}$ \\
\hline Skeletal dysplasia & Rare & Congenital & $\begin{array}{l}\text { X-ray, skeletal dysplasia specialist } \\
\text { consultation }\end{array}$ & $\begin{array}{l}\text { Surgery if indicated for respiratory } \\
\text { issues (rare) }\end{array}$ \\
\hline \multicolumn{5}{|l|}{ Other } \\
\hline Endocrine & $4-6$ & $\begin{array}{l}\text { Infancy to } \\
\text { adulthood }\end{array}$ & $\begin{array}{l}\text { Laboratory testing based on clinical } \\
\text { suspicion }\end{array}$ & Hormone replacement as required \\
\hline Congenital heart disease & Rare & Congenital & $\begin{array}{l}\text { Echocardiogram, chest X-ray, } \\
\text { cardiology consultation }\end{array}$ & Based on specific lesion \\
\hline Hearing loss & $\sim 3$ & $\begin{array}{l}\text { Neonatal to } \\
\text { childhood }\end{array}$ & Audiology evaluation & $\begin{array}{l}\text { Ear tubes for chronic otitis media, } \\
\text { hearing aids, cochlear implants } \\
\text { (rare) }\end{array}$ \\
\hline Cleft palate & $>3$ & Congenital & Craniofacial consultation & Surgery if indicated \\
\hline $\begin{array}{l}\text { Oral features, frenula, } \\
\text { hamartoma }\end{array}$ & $>4$ & Congenital & NA & $\begin{array}{l}\text { Surgery if indicated (for function or } \\
\text { comfort-rare) }\end{array}$ \\
\hline Feeding difficulty, drooling & Common & Congenital & $\begin{array}{l}\text { Clinical feeding evaluation, video } \\
\text { fluoroscopic swallow study }\end{array}$ & $\begin{array}{l}\text { Feeding therapy, tube feeding, } \\
\text { medications for drooling }\end{array}$ \\
\hline \multicolumn{5}{|l|}{ Genetics } \\
\hline Molecular diagnosis & NA & NA & $\begin{array}{l}\text { Genetics consultation, genetic } \\
\text { testing }\end{array}$ & $\begin{array}{l}\text { Prognostic, recurrence risk, and } \\
\text { reproductive counseling, } \\
\text { Stratification into different risk } \\
\text { groups for specific complications, } \\
\text { Assignment to future gene-specific } \\
\text { treatments }\end{array}$ \\
\hline
\end{tabular}

Abbreviations: ADHD, attention deficit hyperactivity disorder; ENT, ear nose throat (otorhinolaryngology); ESKD, end-stage kidney disease; FAF, fundus auto-fluorescence; Hx, history; mvt, movement; PAP, positive airway pressure (continuous, bilevel, or other), PE, physical exam; s/s, signs and symptoms; $\mathrm{T} / \mathrm{A}$, tonsillectomy/adenoidectomy; US, ultrasound.

aBased on Bachmann-Gagescu, Dempsey et al., (2015), the prevalence of each feature likely depends on the specific population evaluated.

bIndividualized Educational Plan (IEP) in the United States.

is no evidence to suggest that antiepileptic treatments should differ from those administered to individuals with non-JS associated epilepsy. While ventriculomegaly is noted relatively frequently on MRIs of individuals with JS, true hydrocephalus requiring treatment is rare. However, since this complication is treatable and can have adverse consequences if left untreated, regular monitoring by measurement of head circumference is recommended in young children. A small number of individuals have dystonic movements (often facial grimacing) and bite their tongues and cheeks. This is a particularly difficult problem, and no successful treatments have been published (Farmer, Deidrick,
Gitten, Fennell, \& Maria, 2006). Apparent temperature regulation problems have also been reported including episodic unexplained fevers (resulting in infectious disease evaluations) and heat intolerance associated with decreased function during hot weather (unpublished observations). The prevalence of these features is unknown.

A variety of behavioral and psychiatric issues have been reported in individuals with JS including tantrums, self-injury, autism, depression, anxiety, and auditory hallucinations (Bachmann-Gagescu, Dempsey, et al., 2015; Bulgheroni et al., 2016; Fennell et al., 1999; Summers et al., 2017). These issues can have an enormous impact on the quality 
TAB LE 3 History and physical exam checklist for managing medical provider

\begin{tabular}{|c|c|c|c|c|}
\hline & $\begin{array}{l}\text { At } \\
\text { diagnosis }\end{array}$ & $\begin{array}{l}\text { Routine } \\
\text { ( yearly) }\end{array}$ & History & Physical examination \\
\hline \multicolumn{5}{|l|}{ Neurologic-head } \\
\hline Encephalocele & $x$ & & "Bump on head?" (usually occipital) & Palpate skull \\
\hline Hydrocephalus & $x$ & $x$ & $\begin{array}{l}\text { Increasing head size }(<2 \mathrm{yr}) \text {, headaches, } \\
\text { vomiting }\end{array}$ & OFC plot, fontanelles \\
\hline Seizures & $x$ & $x$ & $\mathrm{~s} / \mathrm{s}$ & \\
\hline Cognition/psychiatric/behavior & $x$ & $x$ & $\begin{array}{l}\text { Self-injury, anxiety, stereotypies, } \\
\text { depression, ADHD, hallucinations }\end{array}$ & $\begin{array}{l}\text { Std. developmental and psychiatric } \\
\text { assessments, focus on stereotypies, } \\
\text { injury }\end{array}$ \\
\hline \multicolumn{5}{|l|}{ Eyes } \\
\hline Strabismus & $x$ & $x$ & Eye deviation, head tilt & Pupillary alignment, cover-uncover test \\
\hline Ptosis & $x$ & $x$ & $\begin{array}{l}\text { Drooping eyelid, chin-up position } \\
\text { (backward head tilt) }\end{array}$ & $\begin{array}{l}\text { Drooping eyelid, chin-up position } \\
\text { (backward head tilt) }\end{array}$ \\
\hline Retinal dystrophy & $x$ & $x$ & $\begin{array}{l}\text { Visual impairment particularly in low light, } \\
\text { photophobia }\end{array}$ & Visual acuity \\
\hline Coloboma & $x$ & & $\begin{array}{l}\text { Visual impairment (only with macula or } \\
\text { optic nerve involvement) }\end{array}$ & \\
\hline \multicolumn{5}{|l|}{ Respiratory } \\
\hline $\begin{array}{l}\text { Consequences of the MTS: Abnormal } \\
\text { respiratory control }\end{array}$ & $x$ & $x$ & $\begin{array}{l}\text { Apnea, tachypnea, sleep disordered } \\
\text { breathing }\end{array}$ & $\begin{array}{cl}\text { Std. } & \text { Respiratory rhythm } \\
\text { pulmonary } & \text { (awake and asleep) }\end{array}$ \\
\hline \multicolumn{5}{|l|}{ Liver } \\
\hline Congenital hepatic fibrosis & $x$ & $x$ & $\begin{array}{l}\text { s/s portal hypertension, splenomegaly, } \\
\text { varices, Gl bleeding }\end{array}$ & $\begin{array}{l}\text { Splenomegaly, spider angiomata (chest, } \\
\text { arms, and neck) }\end{array}$ \\
\hline \multicolumn{5}{|l|}{ Musculoskeletal } \\
\hline Polydactyly & $x$ & & Functional difficulty & Std. musculoskeletal \\
\hline Scoliosis & $x$ & $x$ & Change in posture & \\
\hline Skeletal Dysplasia & $x$ & & $\begin{array}{l}\text { Short stature, small chest, short limbs, } \\
\text { respiratory status }\end{array}$ & \\
\hline \multicolumn{5}{|l|}{ Other } \\
\hline Endocrine & $x$ & $x$ & $\begin{array}{l}\text { s/s growth failure, hypothyroidism, } \\
\text { diabetes mellitus, micropenis, } \\
\text { abnormal puberty }\end{array}$ & $\begin{array}{l}\text { Heart rate, blood pressure, growth } \\
\text { parameters, genital exam }\end{array}$ \\
\hline Congenital heart disease & $x$ & & $\begin{array}{l}\text { Murmur, feeding, or exercise } \\
\text { intolerance }\end{array}$ & $\begin{array}{l}\text { Heart rate, blood pressure (arm and leg), } \\
\text { oxygen saturation, cardiac exam, } \\
\text { consider echocardiogram }\end{array}$ \\
\hline
\end{tabular}


TABLE 3 (Continued)

\begin{tabular}{lllll} 
& $\begin{array}{l}\text { At } \\
\text { diagnosis }\end{array}$ & $\begin{array}{l}\text { Routine } \\
\text { ( } \text { yearly) }\end{array}$ & History & Physical examination \\
Hearing loss & $\mathrm{X}$ & $\mathrm{X}$ & $\begin{array}{c}\text { Delayed speech, decreased response to } \\
\text { sounds }\end{array}$ & $\begin{array}{c}\text { Newborn and annual hearing } \\
\text { screening }\end{array}$ \\
Cleft palate & $\mathrm{X}$ & $\begin{array}{c}\text { Nasal speech, nasal regurgitation, } \\
\text { feeding difficulties }\end{array}$ & Std. oral \\
Oral features, frenula, hamartoma & $\mathrm{X}$ & $\mathrm{s} / \mathrm{s}$ & \\
\hline
\end{tabular}

Abbreviations: ADHD, attention deficit hyperactivity disorder; MTS, molar tooth sign; mvt, movement; OFC, occipital-frontal circumference; s/s, signs and symptoms; std., standard.

of life for people with JS and their families. Parent-reported Child Behavior Checklist data were available for 45/76 individuals who received a neuropsychological evaluation at $\mathrm{NIH}$. Scores were elevated across all scales except for the externalizing behaviors summary scale (e.g., aggression and tantrums), indicating increased rates of behavioral issues compared to the general population (Summers et al., 2017). Data on psychiatric diagnoses in JS is exceedingly scarce; however, in an Italian cohort of 54 directly-evaluated individuals, 39\% were reported to have behavioral issues, and $7 \%$ were diagnosed with psychiatric conditions (two with oppositional defiant disorder and two with bipolar disorder; Bulgheroni et al., 2016). Within the NIH sample, individuals with JS took psychiatric medications at a higher rate than rates reported in typically developing children and adults; however, the rate of psychiatric medications in individuals with JS appears to be lower than rates reported in other populations with intellectual and developmental disabilities, more generally (Howie, Pastor, \& Lukacs, 2014; Jonas, Gu, \& Albertorio-Diaz, 2013). Furthermore, within the NIH sample, those with JS who had a greater degree of intellectual disability also appear to receive more psychiatric medications (Summers et al., 2017). Circadian rhythm abnormalities and behavioral sleep disturbances have been reported but not formally assessed (Kamdar, Nandkumar, Krishnan, Gamaldo, \& Collop, 2011).

Additional research is needed to fully delineate the spectrum of neurobehavioral and psychiatric issues. Similar to neurobehavioral and psychiatric issues in other populations affected by neurodevelopmental conditions, these issues are treated with behavioral interventions appropriate for the individual (e.g., parent-child interaction therapy, applied behavioral analysis, cognitive-behavioral therapy, and other therapies), counseling, and medications when necessary. Optimizing the treatment of any medical issues is an essential component of neurobehavioral and psychiatric care, since pain and illness can exacerbate behavioral issues.

\subsection{2 | Eyes and vision}

In addition to the neurologically based eye issues mentioned above, visual function may be impacted by coloboma, retinal dysfunction, optic atrophy, and refractive error. Coloboma results from abnormal closure of the optic cup during development, and usually affects the retina or optic nerve, but rarely the iris in JS. Typically, colobomata involving the macula or optic nerve cause visual impairment. Retinal dysfunction in JS is likely the direct result of problems with the photoreceptor outer segment, which is a highly modified cilium. Retinal dystrophy can be apparent at birth or lead to progressive decline in vision due to degenerating photoreceptors. Retinal abnormalities can be confirmed by an ERG (ElectroRetinoGram) which would show decreased electrical responses in the retina, or OCT (Optical Coherence Tomography) which would show abnormal layering of the retina with atrophy. Although poorly detailed in the literature, the retinal dystrophy can range from congenital retinal blindness diagnosed in infancy (Leber Congenital Amaurosis) to a slowly progressive degeneration that can result in nyctalopia (night blindness) or eventual blindness after the second decade (Coene et al., 2009). Retinal involvement (defined as abnormal ERG, abnormal OCT, and/or abnormal retinal pigment with visual impairment) was present in $30 \%$ of individuals in the UW cohort, while coloboma was seen in $\sim 17 \%$ (Bachmann-Gagescu, Dempsey, et al., 2015). In the overlapping, directly evaluated NIH cohort, $24 \%$ had retinal dystrophy, $28 \%$ had coloboma, and $9 \%$ had optic nerve atrophy (Brooks et al., 2018). Some genetic causes (e.g., CEP290 and AHI1 dysfunction) are more likely to be associated with more severe retinal degeneration than others (e.g., INPP5E, MKS1, and NPHP1 dysfunction).

While ptosis is common, it rarely obstructs vision enough to require treatment. Significant refractive error (both myopia and hyperopia) have also been reported and can be treated with corrective spectacles. Patients with significant ("high") myopia should be monitored for retinal detachment by yearly dilated retinal examination. Strabismus (ocular misalignment) is also common and may lead to amblyopia ("lazy eye"), a preventable form of vision loss if caught early enough. Surgical treatment of strabismus should be approached with caution, as the strabismus is often variable in JS (Brooks et al., 2018). Given the potential overlap with Poretti-Boltshauser syndrome (Aldinger et al., 2014; Poretti et al., 2014), high myopia should prompt a re-review of the MRI for cerebellar hemisphere dysplasia, cerebellar cysts, and patchy increased T2/FLAIR signal in the cortical white matter, characteristic of Poretti-Boltshauser syndrome.

Loss of visual function may go unrecognized in individuals with cognitive impairment, further limiting their developmental potential and interaction with the world; therefore, it is important to assess for visual impairment early and provide supportive measures to affected individuals and their families as soon as possible. Interventions should aim at improving quality of life. Ideally, a baseline assessment for the issues described above would be performed by a pediatric ophthalmologist when JS is diagnosed or suspected. Regular follow-up 


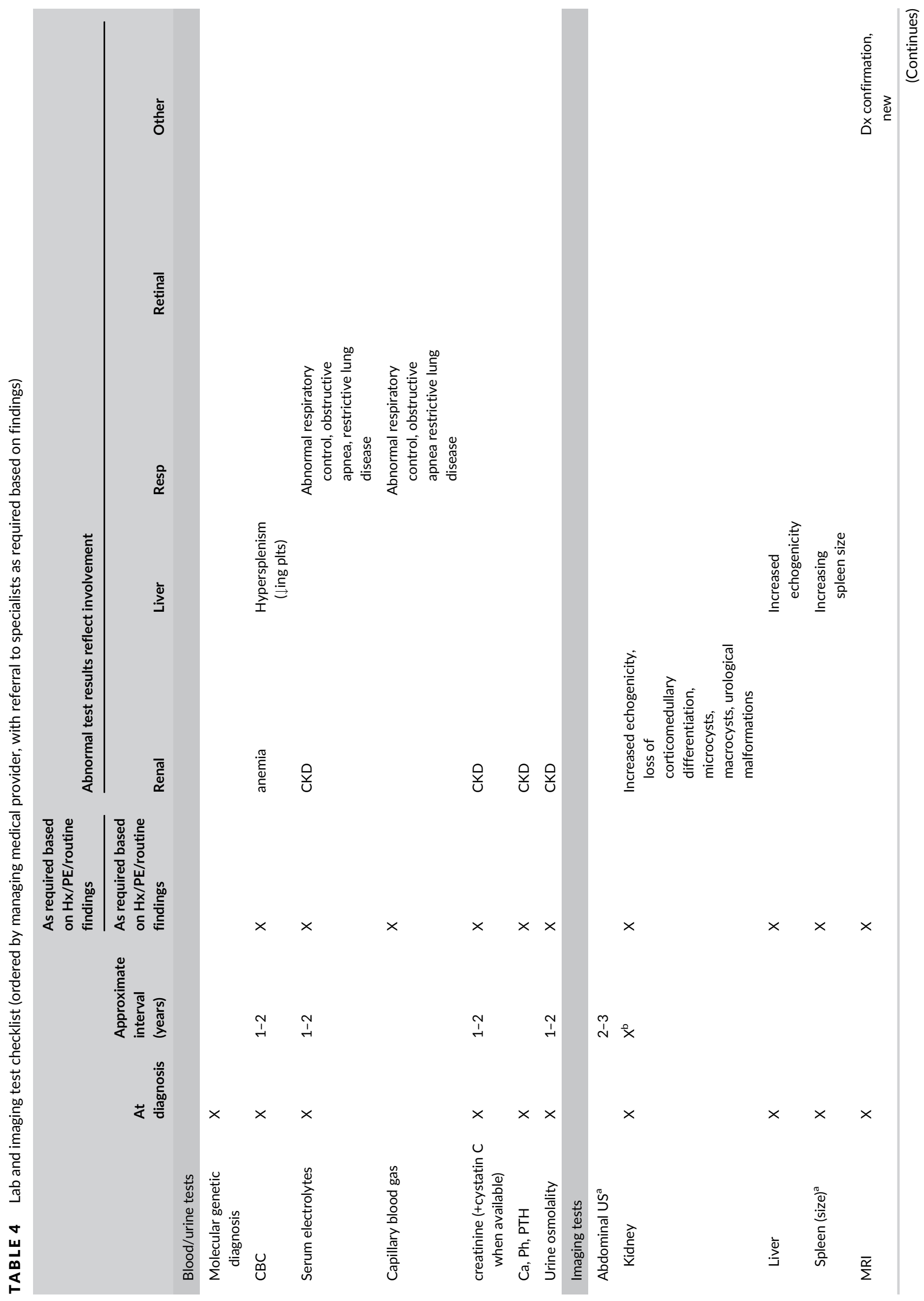




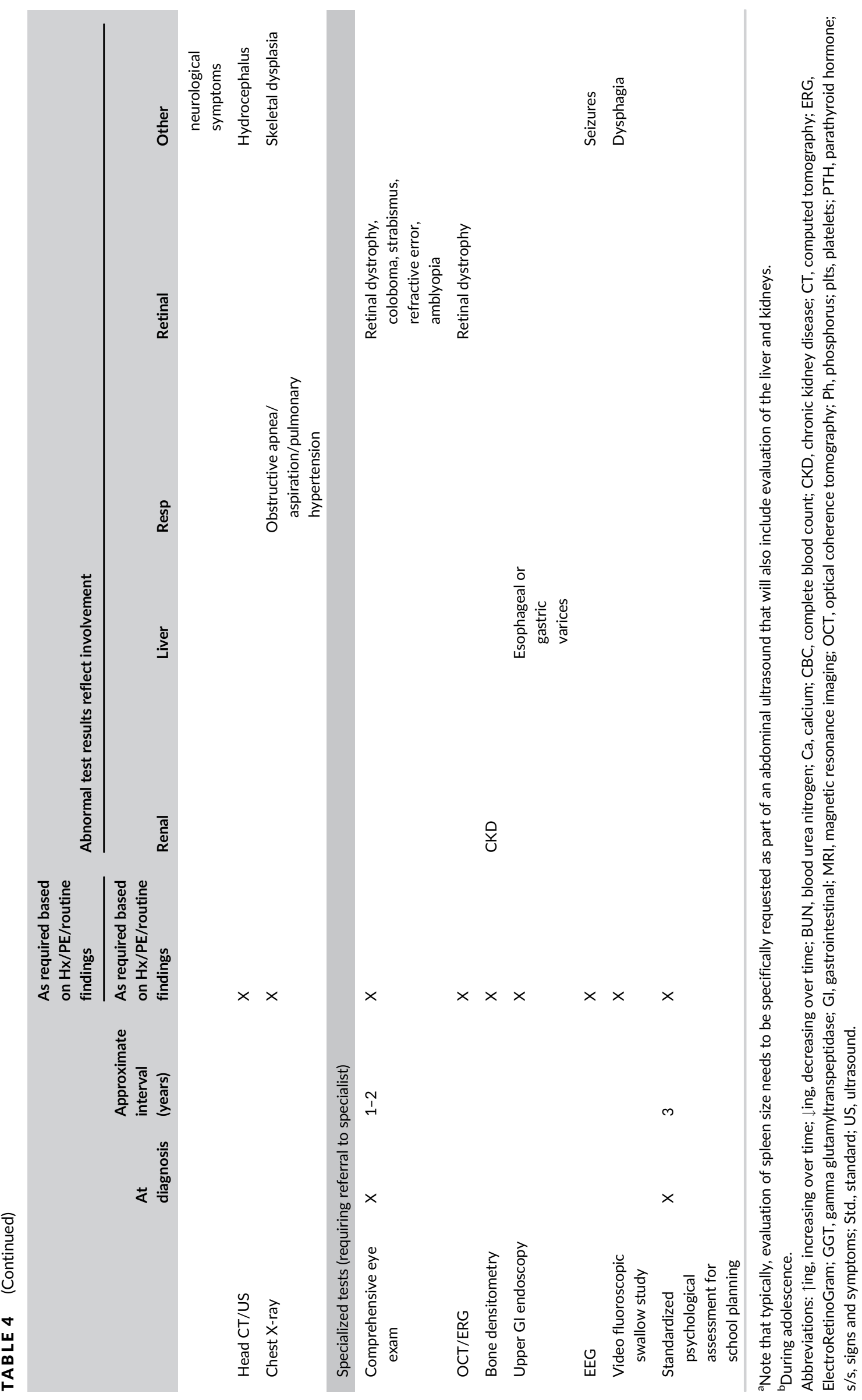


ophthalmological evaluations are warranted for surveillance and treatment of the issues described above.

\subsection{3 | Kidney}

Fibrocystic kidney disease develops in $25-30 \%$ of individuals, and frequently progresses to end-stage renal disease (ESRD; BachmannGagescu, Dempsey, et al., 2015; Fleming et al., 2017). Of the 29 individuals with kidney involvement in the NIH cohort, $31 \%$ had nephronophthisis, 35\% had an overlap-phenotype of autosomal recessive polycystic kidney disease/nephronophthisis, $10 \%$ had a unilateral multicystic dysplastic kidney, and 24\% had indeterminate-type cystic kidney disease (Fleming et al., 2017). Initially, individuals with nephronophthisis may display polyuria and polydipsia. Subsets of individuals can present with a kidney phenotype similar to autosomal recessive polycystic kidney disease with prenatal onset of enlarged kidneys and early onset hypertension (Fleming et al., 2017; GunayAygun et al., 2009). The minimal prevalence for ESRD in the UW cohort was 5.1\% ( $n=30 / 586,24$ received a kidney transplant; Bachmann-Gagescu, Dempsey, et al., 2015), while in an overlapping cohort of individuals evaluated directly, the prevalence was $13 \%$ ( $n=13 / 97,11$ received a kidney transplant; Fleming et al., 2017). Kidney failure appears to be the leading cause of death in JS individuals over 1 year of age, but ESRD has also been observed in infants (Dempsey et al., 2017). Anemia is a common clinical finding in those with nephronophthisis, often noted to be more severe than expected given the level of kidney dysfunction. Poor weight gain or feeding issues can also be associated with kidney dysfunction. While no specific treatments to cure or slow the progression of nephronophthisis are currently available, the goals of early diagnosis are to maintain quality of life and limit complications of chronic kidney disease (CKD) including anemia, bone mineral loss, malnutrition, and poor somatic growth. Although not systematically evaluated, the risk posed by nephrotoxic medications such as aminoglycosides may be increased, so these medications should be avoided when possible. Likewise, nonsteroidal anti-inflammatory drugs should be used with caution.

Individuals should be monitored for signs and symptoms of CKD including at least yearly blood pressure measurements and laboratory testing for serum electrolytes, calcium, phosphorus, creatinine, blood urea nitrogen (BUN), and blood count with hematocrit/hemoglobin. Urine concentrating ability may provide an effective means of monitoring for CKD in JS. In one study of 93 individuals with JS, CKD was predicted in $>75 \%$ with urine osmolality $<600 \mathrm{mOsm} / \mathrm{kg}$, and CKD was significantly increased in patients with an early diagnosis of isolated urinary concentrating defect (Nuovo et al., 2018). Estimated glomerular filtration rate in children (Schwartz et al., 2012) and adults (Levey et al., 2009) should be monitored by serum creatinine or creatinine and cystatin $C$ when available, since cystatin $C$ may be more accurate in patients with limited muscle mass.

Kidney ultrasound may be useful for identifying kidney involvement (altered size, increased echogenicity, loss of corticomedullary differentiation, or overt cysts); however, the value of periodic kidney ultrasounds for follow-up is unclear, since ultrasonographic appearance does not reflect kidney function, which guides medical management. Follow-up for kidney involvement should rely primarily on history, physical examination, and blood and urine tests. Therefore, we recommend a kidney ultrasound at diagnosis to evaluate for genitourinary malformations and establish the presence or absence of kidney involvement. It is reasonable to get a second ultrasound during adolescence, and in addition, kidneys may be evaluated periodically during the abdominal ultrasounds performed to follow spleen size (see below).

\subsection{4 | Liver}

Many individuals with JS have chronically elevated transaminases and GGT (Gamma-glutamyl transferase; Bachmann-Gagescu, Dempsey, et al., 2015; Strongin et al., 2018; Vilboux and others, 2017); however, only a small subset of individuals with JS develop hepatic fibrosis severe enough to result in portal hypertension. Nonetheless, variceal bleeding can be a serious or even fatal complication. In the UW cohort, at least 13 individuals had portal hypertension indicating a minimal prevalence of $2 \%$ (four had splenomegaly, two had esophageal varices, six received a porto-systemic shunt, and three received liver transplantation). In the overlapping NIH cohort, $41 \%$ had elevated liver enzymes and $13 \%$ had probable or definite portal hypertension (Strongin et al., 2018).

The goal of monitoring is to identify and treat portal hypertension to avoid variceal bleeding. Preferred monitoring includes serial platelet measurements looking for a decreasing trend, and serial abdominal ultrasounds (every 2-3 years) looking for abnormal increase in spleen size (Gunay-Aygun et al., 2013). Chronically elevated transaminases and GGT may indicate increased risk for portal hypertension (Strongin et al., 2018). Possible gastrointestinal bleeding in individuals with JS must be evaluated urgently, with strong consideration of endoscopy to evaluate for esophageal varices. Treatment for varices is not JSspecific and can involve sclerotherapy, banding, porto-systemic shunt placement, and liver transplantation may be needed in rare cases.

Differing from cirrhosis, the liver disease in JS and other ciliopathies (congenital hepatic fibrosis) does not impair the synthetic function of the liver (Gunay-Aygun, Gahl, \& Heller, 2008); therefore, individuals with JS do not appear to be at higher risk for complications from hepatotoxic medications, unless they have other risk factors such as hepatitis or liver transplantation. All children with JS should receive vaccinations against hepatitis $A$ and $B$. Liver biopsy is generally not indicated in individuals with confirmed JS, since the results do not change treatment which is focused on the sequelae of portal hypertension. Liver cysts and enlarged intrahepatic bile ducts (e.g., Caroli syndrome), observed in other ciliopathies, have not been seen in JS, so the risk for cholangitis does not appear to be increased.

\subsection{5 | Other gastrointestinal complications}

A subset of individuals has feeding difficulties, likely due to bulbar dysfunction. Aspiration is also frequently reported. Individuals with 
poor weight gain or recurrent respiratory infections should be evaluated for swallow dysfunction and aspiration. Treatment can include feeding therapy from a speech or occupational therapist, and short- or long-term tube feedings may be required. In a large cohort, the minimal prevalence of tube feedings was $10 \%$ ( $8 \%$ G-tube and 2\% nasogastric tube; Bachmann-Gagescu, Dempsey, et al., 2015). Drooling can also be a chronic issue associated with skin breakdown and social difficulties. Treatments can involve positioning, oral-motor therapy, oral medications, and injected botulinum toxin. While a few individuals have been reported with JS and Hirschsprung disease (manifested by intractable constipation), this appears to be a rare or chance association (Brancati et al., 2010; Ozyurek, Kayacik, Gungor, \& Karagoz, 2008). On the other hand, constipation unrelated to Hirschsprung disease is common in JS. Management of constipation should therefore first rely on medical measures, and in case of intractable symptoms, evaluation for Hirschsprung disease and other causes should be initiated.

\subsection{6 | Respiratory}

Abnormal respiratory control has been clearly documented in infants and children with JS by polygraphic recordings, characterized by episodes of apnea, tachypnea, and/or hyperpnea (Boltshauser, Herdan, Dumermuth, \& Isler, 1981; Joubert et al., 1969). Abnormal respiratory patterns and sleep behaviors have also been described more recently by caregiver report (Kamdar et al., 2011), and compared to their siblings (unpublished). Although not explicitly documented in the literature, our experience indicates that the respiratory control abnormalities improve with age in most patients. Nonetheless, in some individuals, respiratory control abnormalities are severe enough to warrant chronic ventilation (Mercado, Pedraza, Mayol, Rodriguez Santana, \& Tejeda, 1991). In a retrospective study of individuals with JS who had died, apnea and respiratory failure were the leading causes of death in children under 1 year of age but were also the cause of death in multiple individuals older than 1 year of age (Dempsey et al., 2017). Older children and adults with JS have an increased risk of central and obstructive sleep-disordered breathing compared to population data, especially if they are obese (Andermann, Andermann, Ptito, Fontaine, \& Joubert, 1999; Wolfe, Lakadamyali, \& Mutlu, 2010). Sleep-disordered breathing can also cause or worsen neurobehavioral issues (Witmans \& Young, 2011), and if untreated, lead to pulmonary hypertension. No systematic data exist to guide monitoring, but at a minimum, surveillance should include yearly history and examination for sleep and breathing disturbances. Capillary blood gas and electrolytes in younger children and those with obesity can help identify hypoventilation. Sleep medicine consultation or polysomnography should be considered for symptomatic individuals. Rare individuals with JS additionally have restrictive lung disease due to co-existing skeletal dysplasia such as Jeune syndrome (Halbritter et al., 2013; Lehman et al., 2010; Shaheen et al., 2015; Tuz et al., 2014). Several male individuals with hemizygous OFD1 variants have been reported to have recurrent respiratory infections similar to individuals with primary ciliary dyskinesia (unpublished; Budny et al., 2006; Coene et al., 2009;
Hannah et al., 2019); however, additional research is required to determine whether individuals with JS are at increased risk for respiratory issues due to abnormal mucociliary clearance. Clinicians should consider evaluation for primary ciliary dyskinesia in individuals with JS and recurrent respiratory infections. Severely affected individuals are at risk for chronic respiratory failure and aspiration pneumonia.

\subsection{7 | Endocrine}

Various endocrinological abnormalities are increased in individuals with JS, such as central diabetes insipidus, premature puberty, hypothyroidism, growth hormone deficiency, and/or panhypopituitarism, affecting together 4\% (Bachmann-Gagescu, Dempsey, et al., 2015). An additional 1-2\% have Type I diabetes mellitus, hypothyroidism, polycystic ovarian syndrome, and ovarian "failure" which may or may not be increased in JS. Short stature and growth hormone deficiency have also been reported (Bachmann-Gagescu, Dempsey, et al., 2015; Stephen et al., 2017; Vilboux, Malicdan, et al., 2017); therefore, we recommend closely monitoring for symptoms of hypothyroidism, dehydration or fluid overload, poor linear growth, and precocious or delayed pubertal development. As noted above, problems with linear growth or polyuria/urinary concentrating defects may also be related to kidney involvement.

\subsection{8 | Musculoskeletal}

Similar to other individuals with hypotonia, those with JS have an increased risk for scoliosis which is present in at least $5 \%$ of individuals (Bachmann-Gagescu, Dempsey, et al., 2015); however, it rarely requires treatment. Monitoring for scoliosis by physical examination should be performed every 1-2 years until growth is complete. Referral to an orthopedic surgeon is indicated if the scoliosis may progress to the point that it causes restrictive respiratory disease, difficulty with upright posture, and/or pain. Fifteen percent of individuals have polydactyly (Bachmann-Gagescu, Dempsey, et al., 2015) that can be left alone or surgically addressed, depending on the stability of the extra digits, difficulty fitting into shoes and gloves, and family preference. In a few families, skeletal dysplasia is present in addition to typical JS features, so that a mixed Joubert-Jeune syndrome phenotype is observed (Bachmann-Gagescu, Phelps, et al., 2015; Halbritter et al., 2013; Malicdan et al., 2015; Tuz et al., 2014).

\subsection{9 | Cardiovascular}

Rare individuals with severe complex congenital heart disease have been reported (Karp, Grosse-Wortmann, \& Bowdin, 2012); however, only $1-2 \%$ of individuals have congenital heart disease, including atrial septal defect, coarctation of the aorta, bicuspid aortic valve, and aortic stenosis (Bachmann-Gagescu, Dempsey, et al., 2015). Individuals with murmurs, cyanosis, poor perfusion, and other manifestations of possible 
congenital heart disease should be evaluated by a pediatric cardiologist. The utility of a screening echocardiogram has not been evaluated. In the United States, screening all newborns for congenital heart disease by physical examination and pulse oximetry is recommended as part of standard newborn screening programs (Oster et al., 2016).

\subsubsection{0 $\quad$ Ear, nose, and throat}

A variety of oral manifestations including tongue hamartomas, additional frenulae (under the tongue and between the cheeks and gums), and cleft lip/palate have been reported, illustrating the phenotypic overlap between JS and oral-facial-digital syndrome(s) (Poretti et al., 2012; Thauvin-Robinet et al., 2014). In a small cohort of 22 individuals with JS, conductive hearing loss was reported in six, and mild sensorineural hearing loss was reported in three, all of them older than 17 years of age (Kroes et al., 2010). In contrast, the prevalence of hearing loss in a larger cohort was $3 \%$, which is still substantially higher than the 1-2/1,000 population prevalence in children (Bachmann-Gagescu, Dempsey, et al., 2015; Fortnum, Summerfield, Marshall, Davis, \& Bamford, 2001). No systematic data indicate that individuals with JS should be screened for hearing loss differently than other individuals; however, it is important to have a low threshold for audiology evaluation, since many forms of hearing loss are treatable, and even mild hearing loss can adversely affect speech/language development.

\subsubsection{1 | Sedation and anesthesia}

Individuals with JS may require sedation for a variety of procedures, most commonly dental care. Given their known structural abnormalities of the brainstem, central respiratory control problems, airway hypotonia and swallow dysfunction, they should be considered high risk for anesthesia. In at least 20 individuals reported in the literature, apnea is a common complication, sometimes requiring airway intervention such as intubation or mask airway (Atalay, Soylu, \& Tekcan, 2016; Bhaskar et al., 2013; Buntenbroich \& Dullenkopf, 2013a, 2013b; Galante, Meola, Cinnella, \& Dambrosio, 2009; Habre, Sims, \& D'Souza, 1997; Matthews, 1989; Platis et al., 2006; Sriganesh et al., 2014; Sriganesh, Smita, \& Aravind, 2010; Vodopich \& Gordon, 2004). Some authors suggest avoiding sedatives known to be associated with central respiratory depression, and avoiding unnecessary conscious sedation for brief, uncomplicated procedures such as MRI when possible; however, insufficient evidence exists to provide specific guidelines for individuals with JS. To ensure timely and appropriate management of potential complications, interventions that require sedation or anesthesia should be performed at hospitals equipped to handle any complications that may ensue.

Individuals with JS often have complex medical histories, making it imperative for them to be evaluated by an anesthesiology professional well in advance of elective sedation or anesthesia. This allows time for appropriate clinical evaluation and any required additional testing, ensuring that the anesthesiology professional and facility are as prepared as possible. Meeting with the family can also help educate the anesthesiology professional about the affected individual and about JS, since it is a rare condition and likely not well known to the provider. When anesthesia consultation is not possible prior to the procedure, it is imperative to ask for the anesthesia professional to meet the individual and the caregiver on the day of surgery. A full health history should be reviewed including medical issues, prior anesthetic exposures, and current medications (including any supplements). Allowing a caregiver to accompany an affected individual during induction of anesthesia may minimize pretreatment with sedatives. In addition, we recommend adherence to procedures for high-risk individuals and prolonged observation after sedation to evaluate for apnea.

\subsection{Genetic counseling}

Genetic counseling about the mechanism of inheritance, recurrence risk, genetic testing, and reproductive options is the standard of care for individuals with JS and their families. To date, only autosomal recessive and $\mathrm{X}$-linked inheritance mechanisms have been demonstrated for JS. With autosomal recessive inheritance, parents of an affected child have a $25 \%$ recurrence risk with each pregnancy, and unaffected siblings have a $67 \%$ risk of being carriers. Since the carrier frequency for any given JS gene in outbred populations is $<1 / 500$, the risk of a carrier having an affected child with an unrelated partner in outbred populations is $<1 / 2,000$. For the one X-linked gene (OFD1), the recurrence risk is also $25 \%$ ( $50 \%$ of sons); $50 \%$ of unaffected daughters are carriers, and all unaffected sons are noncarriers. Recurrence risk counseling in consanguineous and founder populations (e.g., Ashkenazi Jews, Hutterites, French Canadians, and others) require individualized calculations. While little is known about fertility in individuals with JS, several women have had children; therefore, teenagers and adults with JS should be counseled about recurrence risk for people with rare recessive conditions at a level appropriate to their understanding. Oligogenic inheritance, where variants in $>1$ gene are required to cause a disorder, has been proposed to play a role in ciliopathies (Hoefele et al., 2007; Katsanis et al., 2001), but no definitive examples have been published in JS (Abu-Safieh et al., 2012; Phelps et al., 2018); therefore, we recommend against clinical counseling for oligogenic inheritance at this time. For details about molecular confirmation of the diagnosis, see the Section 2.2 above.

Reproductive options for couples with a prior child or fetus affected by JS are best explored through formal genetic counseling. Options to reduce the risk of having a second affected child may include preimplanation genetic diagnosis for a known pathogenic variant, use of donor egg or sperm, prenatal diagnosis through chorionic villus sampling or amniocentesis, or adoption. Couples considering gamete donation should avoid donation by relatives, given their increased risk of being carriers for the same pathogenic variant. For couples in whom the cause is unknown, egg donation may be preferred over sperm donation since the mother may be a carrier for a pathogenic OFD1 variant. Prenatal imaging such as ultrasound and fetal MRI may be used to evaluate for features of JS during 
pregnancy. Imaging abnormalities may suggest a diagnosis of JS, but the absence of abnormalities is not a guarantee that the fetus is unaffected. The decision to pursue or decline alternative reproductive options is very personal, and discussion with a geneticist or genetic counselor may provide an opportunity to explore all available options. In the United States, genetic counseling providers can be identified through the National Society of Genetic Counselors (www.nsgc.org).

\section{5 | Adjusted follow-up recommendations based on gene-phenotype associations}

While general healthcare recommendations apply to all individuals with JS, gene-phenotype correlations can be used to adjust management based on the specific underlying genetic etiology. CEP290 dysfunction is strongly associated with retinal dystrophy and to a lesser extent kidney disease; therefore, individuals with CEP290-related JS should have more frequent monitoring for retinal and kidney disease as described above. Similarly, loss of TMEM67 function is strongly associated with coloboma and liver fibrosis (Bachmann-Gagescu, Dempsey, et al., 2015; Brancati et al., 2007, 2009; Doherty et al., 2010; Vilboux and others, 2017), so monitoring for liver fibrosis should be performed more frequently. Weaker associations also support a higher risk for retinal disease with AHI1, and kidney disease with TMEM67 and RPGRIP1L. Conversely, individuals with loss of TMEM67 function appear less likely to develop retinal disease; consequently, less frequent monitoring of retinal involvement may be acceptable in these individuals (BachmannGagescu, Dempsey, et al., 2015).

\section{6 | Precision treatments}

Precision treatments are treatments specifically targeting the genetic cause or biological mechanism of a disorder. Currently, precision treatments for JS are only available as part of research studies, if at all. Although not yet used for targeting a JS gene, gene therapy has been used to improve visual function for specific types of retinal dystrophy by direct retinal injection of expression vectors in humans (Russell et al., 2017). Future trials are likely to involve the CEP290 gene, a major cause of Leber congenital amaurosis and JS (Maeder et al., 2019; Mookherjee et al., 2018). Alternatively, antisense oligonucleotides can augment gene function by blocking aberrant splicing (Cideciyan et al., 2019; Dulla et al., 2018) or by causing exons with deleterious variants to be skipped (Ramsbottom et al., 2018). These treatments are still in early development for JS, but have been used for other disorders in humans such as spinal muscular atrophy (Finkel et al., 2017). Future medications targeting specific pathways that are disrupted in JS may be beneficial, but this work is also in its infancy (Hynes et al., 2014; Kim et al., 2018). Some promising medications developed for ciliopathy-related conditions in animal models have been ineffective or harmful in humans (Ruggenenti et al., 2016; Serra et al., 2010; Walz et al., 2010); therefore, cautious optimism is in order about the timeline for future effective treatments.

\section{$2.7 \quad$ Family support}

While caring for a loved one with significant healthcare needs and/or neurodevelopmental disability is often very rewarding, it can also be emotionally and cognitively challenging. Families in need can draw support from other family members, medical providers, mental health providers, social workers, community resources, and family support organizations like the Joubert Syndrome and Related Disorders Foundation (https://jsrdf.org), the Asociación de Familias con Síndrome de Joubert y Trastornos Relacionados (https://asociacionfabert.wixsite. com/fabert), Associazione Italiana Sindrome di Joubert e Atassie Congenite (http://www.aisjac.net), and the Ciliopathy Alliance (www. ciliopathyalliance.org). In addition, "respite care" can provide primary caregiver(s) breaks from caring for others so that they can rest and care for themselves. Information about respite care resources is available from a variety of providers, and at https://www.childwelfare. gov/topics/preventing/prevention-programs/respite/ and https:// archrespite.org/respitelocator for the United States.

\section{3 | CONCLUSIONS}

Given the multisystem nature of JS in the majority of individuals, ideal clinical management requires careful regular follow up for early detection and optimal management of complications. To assist families in receiving the best medical care possible, one provider should take the lead, performing the baseline and follow-up evaluations (Tables 2-4), and referring the individual for specialized care when specific organs are involved. In this manner, all the relevant information for a given individual can be centralized for coordination of care. In addition to diagnostic, carrier, and prenatal testing, a molecular diagnosis allows prognostic substratification that can guide monitoring and treatment of progressive features. Moreover, gene-specific treatments may become available in the future and will require the knowledge of the gene defect in each individual.

Ongoing research is required to identify all of the genetic causes of JS so that every individual can receive a genetic diagnosis and ultimately precision healthcare tailored to that diagnosis. Further study of phenotypic outcomes will allow more precise prognostic information, including more accurate estimates of the age of onset and longterm evolution for each of the progressive features. In addition, lesscharacterized phenotypic features require systematic assessment, in particular, the behavioral and psychiatric issues that often present major problems for the affected individual and their family. Finally, existing supportive treatments need to be optimized and precision treatments need to be developed and implemented.

\section{ACKNOWLEDGMENTS}

During the long process of drafting these healthcare recommendations, Andrea Poretti, MD died suddenly. Andrea was a brilliant child neurologist with extensive neuroimaging expertise who was very devoted to his patients, research colleagues, and family. He is deeply missed by all. 


\section{CONFLICT OF INTEREST}

F.H. is a cofounder and SAB member of Goldfinch-Bio.

\section{DATA AVAILABILITY STATEMENT}

Data sharing is not applicable to this article as no new data were created or analyzed in this study.

\section{ORCID}

Jennifer C. Dempsey (D) https://orcid.org/0000-0002-5937-5830 Friedhelm Hildebrandt (ID https://orcid.org/0000-0002-7130-0030 Angela C. Summers (D) https://orcid.org/0000-0002-0123-0794 Dan Doherty (D) https://orcid.org/0000-0001-9377-028X

\section{REFERENCES}

Abu-Safieh, L., Al-Anazi, S., Al-Abdi, L., Hashem, M., Alkuraya, H., Alamr, M., ... Alkuraya, F. S. (2012). In search of triallelism in BardetBiedl syndrome. European Journal of Human Genetics, 20(4), 420-427.

Akizu, N., Silhavy, J. L., Rosti, R. O., Scott, E., Fenstermaker, A. G., Schroth, J., ... Gleeson, J. G. (2014). Mutations in CSPP1 lead to classical Joubert syndrome. American Journal of Human Genetics, 94(1), 80-86.

Aldinger, K. A., Mosca, S. J., Tetreault, M., Dempsey, J. C., Ishak, G. E., Hartley, T., ... Doherty, D. (2014). Mutations in LAMA1 cause cerebellar dysplasia and cysts with and without retinal dystrophy. American Journal of Human Genetics, 95(2), 227-234.

Alkanderi, S., Molinari, E., Shaheen, R., Elmaghloob, Y., Stephen, L. A., Sammut, V., ... Sayer, J. A. (2018). ARL3 mutations cause Joubert syndrome by disrupting ciliary protein composition. American Journal of Human Genetics, 103(4), 612-620.

Andermann, F., Andermann, E., Ptito, A., Fontaine, S., \& Joubert, M. (1999). History of Joubert syndrome and a 30-year follow-up of the original proband. Journal of Child Neurology, 14(9), 565-569.

Arts, H. H., Doherty, D., van Beersum, S. E., Parisi, M. A., Letteboer, S. J., Gorden, N. T., ... Roepman, R. (2007). Mutations in the gene encoding the basal body protein RPGRIP1L, a nephrocystin-4 interactor, cause Joubert syndrome. Nature Genetics, 39(7), 882-888.

Aslan, H., Ulker, V., Gulcan, E. M., Numanoglu, C., Gul, A., Agar, M., \& Ark, H. C. (2002). Prenatal diagnosis of Joubert syndrome: A case report. Prenatal Diagnosis, 22(1), 13-16.

Atalay, Y. O., Soylu, A. I., \& Tekcan, D. (2016). Anaesthesia and orphan disease: Sedation with ketofol in two patients with Joubert syndrome. European Journal of Anaesthesiology, 33(11), 868-869.

Baala, L., Romano, S., Khaddour, R., Saunier, S., Smith, U. M., Audollent, S., ... Attie-Bitach, T. (2007). The Meckel-Gruber syndrome gene, MKS3, is mutated in Joubert syndrome. American Journal of Human Genetics, 80(1), 186-194.

Bachmann-Gagescu, R., Dempsey, J. C., Phelps, I. G., O'Roak, B. J., Knutzen, D. M., Rue, T. C., ... Doherty, D. (2015). Joubert syndrome: A model for untangling recessive disorders with extreme genetic heterogeneity. Journal of Medical Genetics, 52(8), 514-522.

Bachmann-Gagescu, R., Phelps, I. G., Dempsey, J. C., Sharma, V. A., Ishak, G. E., Boyle, E. A., ... Doherty, D. (2015). KIAA0586 is Mutated in Joubert Syndrome. Human Mutation, 36(9), 831-835.

Beck, B. B., Phillips, J. B., Bartram, M. P., Wegner, J., Thoenes, M., Pannes, A., ... Bolz, H. J. (2014). Mutation of POC1B in a severe syndromic retinal ciliopathy. Human Mutation, 35(10), 1153-1162.

Bhaskar, P., John, J., Sivamurthy, S. K., Lone, R. A., Tysarowski, P. A., Riyas, M. K., ... Sallehuddin, A. (2013). Anesthetic management of an infant with Joubert syndrome for cardiac surgery. Journal of Clinical Anesthesia, 25(6), 488-490.
Bielas, S. L., Silhavy, J. L., Brancati, F., Kisseleva, M. V., Al-Gazali, L., Sztriha, L., ... Gleeson, J. G. (2009). Mutations in INPP5E, encoding inositol polyphosphate-5-phosphatase E, link phosphatidyl inositol signaling to the ciliopathies. Nature Genetics, 41(9), 1032-1036.

Boltshauser, E., Herdan, M., Dumermuth, G., \& Isler, W. (1981). Joubert syndrome: Clinical and polygraphic observations in a further case. Neuropediatrics, 12(2), 181-191.

Braddock, B. A., Farmer, J. E., Deidrick, K. M., Iverson, J. M., \& Maria, B. L. (2006). Oromotor and communication findings in joubert syndrome: Further evidence of multisystem apraxia. Journal of Child Neurology, 21(2), 160-163.

Braddock, S. R., Henley, K. M., \& Maria, B. L. (2007). The face of Joubert syndrome: A study of dysmorphology and anthropometry. American Journal of Medical Genetics Part A, 143A(24), 3235-3242.

Brancati, F., Barrano, G., Silhavy, J. L., Marsh, S. E., Travaglini, L., Bielas, S. L., ... Gleeson, J. G. (2007). CEP290 mutations are frequently identified in the oculo-renal form of Joubert syndrome-related disorders. American Journal of Human Genetics, 81(1), 104-113.

Brancati, F., Dallapiccola, B., \& Valente, E. M. (2010). Joubert Syndrome and related disorders. Orphanet Journal of Rare Diseases, 5, 20.

Brancati, F., lannicelli, M., Travaglini, L., Mazzotta, A., Bertini, E., Boltshauser, E., ... Valente, E. M. (2009). MKS3/TMEM67 mutations are a major cause of $\mathrm{COACH}$ Syndrome, a Joubert Syndrome related disorder with liver involvement. Human Mutation, 30(2), E432-E442.

Brooks, B. P., Zein, W. M., Thompson, A. H., Mokhtarzadeh, M., Doherty, D. A., Parisi, M., ... Gunay-Aygun, M. (2018). Joubert syndrome: Ophthalmological findings in correlation with genotype and hepatorenal disease in 99 patients prospectively evaluated at a single center. Ophthalmology, 125(12), 1937-1952.

Bruel, A. L., Franco, B., Duffourd, Y., Thevenon, J., Jego, L., Lopez, E., ... Thauvin-Robinet, C. (2017). Fifteen years of research on oral-facialdigital syndromes: From 1 to 16 causal genes. Journal of Medical Genetics, 54(6), 371-380.

Bruel, A. L., Levy, J., Elenga, N., Defo, A., Favre, A., Lucron, H., ... Verloes, A. (2018). INTU-related oral-facial-digital syndrome type VI: A confirmatory report. Clinical Genetics, 93(6), 1205-1209.

Budny, B., Chen, W., Omran, H., Fliegauf, M., Tzschach, A., Wisniewska, M., ... Ropers, H. H. (2006). A novel X-linked recessive mental retardation syndrome comprising macrocephaly and ciliary dysfunction is allelic to oral-facial-digital type I syndrome. Human Genetics, 120(2), 171-178.

Bulgheroni, S., D'Arrigo, S., Signorini, S., Briguglio, M., Di Sabato, M. L., Casarano, M., ... Riva, D. (2016). Cognitive, adaptive, and behavioral features in Joubert syndrome. American Journal of Medical Genetics Part A, 170(12), 3115-3124.

Buntenbroich, S., \& Dullenkopf, A. (2013a). Anesthesia recommendations for patients suffering from Joubert syndrome. In T. Münster (Ed.), Orphananesthesia. https://www.orpha.net/data/patho/Pro/en/Joubert_ EN.pdf

Buntenbroich, S., \& Dullenkopf, A. (2013b). Total intravenous anesthesia in a patient with Joubert-Boltshauser syndrome. Paediatric Anaesthesia, 23(2), 204-205.

Cantagrel, V., Silhavy, J. L., Bielas, S. L., Swistun, D., Marsh, S. E., Bertrand, J. Y., ... Gleeson, J. G. (2008). Mutations in the cilia gene ARL13B lead to the classical form of Joubert syndrome. American Journal of Human Genetics, 83(2), 170-179.

Chaki, M., Airik, R., Ghosh, A. K., Giles, R. H., Chen, R., Slaats, G. G., ... Hildebrandt, F. (2012). Exome capture reveals ZNF423 and CEP164 mutations, linking renal ciliopathies to DNA damage response signaling. Cell, 150(3), 533-548.

Chevrier, V., Bruel, A. L., Van Dam, T. J., Franco, B., Lo Scalzo, M., Lembo, F., ... Thauvin-Robinet, C. (2016). OFIP/KIAA0753 forms a complex with OFD1 and FOR20 at pericentriolar satellites and centrosomes and is mutated in one individual with 
oral-facial-digital syndrome. Human Molecular Genetics, 25(3), 497-513.

Cideciyan, A. V., Jacobson, S. G., Drack, A. V., Ho, A. C., Charng, J., Garafalo, A. V., ... Russell, S. R. (2019). Effect of an intravitreal antisense oligonucleotide on vision in Leber congenital amaurosis due to a photoreceptor cilium defect. Nature Medicine, 25(2), 225-228.

Coene, K. L., Roepman, R., Doherty, D., Afroze, B., Kroes, H. Y., Letteboer, S. J., ... de Brouwer, A. P. (2009). OFD1 is mutated in Xlinked Joubert syndrome and interacts with LCA5-encoded lebercilin. American Journal of Human Genetics, 85(4), 465-481.

Dafinger, C., Liebau, M. C., Elsayed, S. M., Hellenbroich, Y., Boltshauser, E., Korenke, G. C., ... Bolz, H. J. (2011). Mutations in KIF7 link Joubert syndrome with Sonic Hedgehog signaling and microtubule dynamics. The Journal of Clinical Investigation, 121(7), 2662-2667.

Davis, E. E., Zhang, Q., Liu, Q., Diplas, B. H., Davey, L. M., Hartley, J., ... Katsanis, N. (2011). TTC21B contributes both causal and modifying alleles across the ciliopathy spectrum. Nature Genetics, 43(3), 189-196.

De Mori, R., Romani, M., D'Arrigo, S., Zaki, M. S., Lorefice, E., Tardivo, S., ... Valente, E. M. (2017). Hypomorphic recessive variants in SUFU impair the Sonic Hedgehog Pathway and cause Joubert Syndrome with cranio-facial and skeletal defects. American Journal of Human Genetics, 101(4), 552-563.

Delous, M., Baala, L., Salomon, R., Laclef, C., Vierkotten, J., Tory, K., ... Saunier, S. (2007). The ciliary gene RPGRIP1L is mutated in cerebellooculo-renal syndrome (Joubert syndrome type B) and Meckel syndrome. Nature Genetics, 39(7), 875-881.

Dempsey, J. C., Phelps, I. G., Bachmann-Gagescu, R., Glass, I. A., Tully, H. M., \& Doherty, D. (2017). Mortality in Joubert syndrome. American Journal of Medical Genetics Part A, 173(5), 1237-1242.

Dixon-Salazar, T., Silhavy, J. L., Marsh, S. E., Louie, C. M., Scott, L. C., Gururaj, A., ... Gleeson, J. G. (2004). Mutations in the AHI1 gene, encoding Jouberin, cause Joubert syndrome with cortical polymicrogyria. American Journal of Human Genetics, 75(6), 979-987.

Dixon-Salazar, T. J., Silhavy, J. L., Udpa, N., Schroth, J., Bielas, S., Schaffer, A. E., ... Gleeson, J. G. (2012). Exome sequencing can improve diagnosis and alter patient management. Science Translational Medicine, 4(138), 138ra178.

Doherty, D. (2009). Joubert syndrome: Insights into brain development, cilium biology, and complex disease. Seminars in Pediatric Neurology, 16(3), 143-154.

Doherty, D., Glass, I. A., Siebert, J. R., Strouse, P. J., Parisi, M. A., Shaw, D. W., ... Nyberg, D. (2005). Prenatal diagnosis in pregnancies at risk for Joubert syndrome by ultrasound and MRI. Prenatal Diagnosis, 25(6), 442-447.

Doherty, D., Parisi, M. A., Finn, L. S., Gunay-Aygun, M., Al-Mateen, M., Bates, D., ... Glass, I. A. (2010). Mutations in 3 genes (MKS3, CC2D2A and RPGRIP1L) cause $\mathrm{COACH}$ syndrome (Joubert syndrome with congenital hepatic fibrosis). Journal of Medical Genetics, 47(1), 8-21.

Dulla, K., Aguila, M., Lane, A., Jovanovic, K., Parfitt, D. A., Schulkens, I., ... Cheetham, M. E. (2018). Splice-modulating oligonucleotide QR-110 restores CEP290 mRNA and function in human c.2991+1655A>G LCA10 models. Molecular Therapy Nucleic Acids, 12, 730-740.

Edvardson, S., Shaag, A., Zenvirt, S., Erlich, Y., Hannon, G. J., Shanske, A. L., ... Elpeleg, O. (2010). Joubert syndrome 2 (JBTS2) in Ashkenazi Jews is associated with a TMEM216 mutation. American journal of human genetics, 86(1), 93-97.

Enokizono, M., Aida, N., Niwa, T., Osaka, H., Naruto, T., Kurosawa, K., ... Matsumoto, N. (2017). Neuroimaging findings in Joubert syndrome with C5orf42 gene mutations: A milder form of molar tooth sign and vermian hypoplasia. Journal of the Neurological Sciences, 376, 7-12.

Farmer, J. E., Deidrick, K. M., Gitten, J. C., Fennell, E. B., \& Maria, B. L. (2006). Parenting stress and its relationship to the behavior of children with Joubert syndrome. Journal of Child Neurology, 21(2), 163-167.

Fennell, E. B., Gitten, J. C., Dede, D. E., \& Maria, B. L. (1999). Cognition, behavior, and development in Joubert syndrome. Journal Child Neurology, 14(9), 592-596.

Ferland, R. J., Eyaid, W., Collura, R. V., Tully, L. D., Hill, R. S., Al-Nouri, D., ... Walsh, C. A. (2004). Abnormal cerebellar development and axonal decussation due to mutations in AHI1 in Joubert syndrome. Nature Genetics, 36(9), 1008-1013.

Finkel, R. S., Mercuri, E., Darras, B. T., Connolly, A. M., Kuntz, N. L., Kirschner, J., ... De Vivo, D. C. (2017). Nusinersen versus sham control in infantile-onset spinal muscular atrophy. The New England Journal of Medicine, 377(18), 1723-1732.

Fleming, L. R., Doherty, D. A., Parisi, M. A., Glass, I. A., Bryant, J., Fischer, R., ... Gunay-Aygun, M. (2017). Prospective evaluation of kidney disease in Joubert syndrome. Clinical journal of the American Society of Nephrology, 12(12), 1962-1973.

Fluss, J., Blaser, S., Chitayat, D., Akoury, H., Glanc, P., Skidmore, M., \& Raybaud, C. (2006). Molar tooth sign in fetal brain magnetic resonance imaging leading to the prenatal diagnosis of Joubert syndrome and related disorders. Journal of Child Neurology, 21(4), 320-324.

Fortnum, H. M., Summerfield, A. Q., Marshall, D. H., Davis, A. C., \& Bamford, J. M. (2001). Prevalence of permanent childhood hearing impairment in the United Kingdom and implications for universal neonatal hearing screening: Questionnaire based ascertainment study. BMJ, 323(7312), 536-540.

Galante, D., Meola, S., Cinnella, G., \& Dambrosio, M. (2009). Regional caudal blockade in a pediatric patient affected by the Joubert syndrome. Acta Anaesthesiologica Scandinavica, 53(5), 693-694.

Garcia-Gonzalo, F. R., Corbit, K. C., Sirerol-Piquer, M. S., Ramaswami, G., Otto, E. A., Noriega, T. R., ... Reiter, J. F. (2011). A transition zone complex regulates mammalian ciliogenesis and ciliary membrane composition. Nature Genetics, 43(8), 776-784.

Gitten, J., Dede, D., Fennell, E., Quisling, R., \& Maria, B. L. (1998). Neurobehavioral development in Joubert syndrome. Journal of Child Neurology, 13(8), 391-397.

Gorden, N. T., Arts, H. H., Parisi, M. A., Coene, K. L., Letteboer, S. J., van Beersum, S. E., ... Doherty, D. (2008). CC2D2A is mutated in Joubert syndrome and interacts with the ciliopathy-associated basal body protein CEP290. American Journal of Human Genetics, 83(5), 559-571.

Gunay-Aygun, M., Font-Montgomery, E., Lukose, L., Tuchman Gerstein, M., Piwnica-Worms, K., Choyke, P., ... Heller, T. (2013). Characteristics of congenital hepatic fibrosis in a large cohort of patients with autosomal recessive polycystic kidney disease. Gastroenterology, 144(1), 112-121.

Gunay-Aygun, M., Gahl, W. A., \& Heller, T. (2008). Congenital hepatic fibrosis overview. In M. P. Adam, H. H. Ardinger, R. A. Pagon, S. E. Wallace, B. LJH, K. Stephens, \& A. Amemiya (Eds.). Seattle, WA: GeneReviews((R)). https://www.ncbi.nlm.nih.gov/books/NBK2701/

Gunay-Aygun, M., Parisi, M. A., Doherty, D., Tuchman, M., Tsilou, E., Kleiner, D. E., ... Gahl, W. A. (2009). MKS3-related ciliopathy with features of autosomal recessive polycystic kidney disease, nephronophthisis, and Joubert Syndrome. The Journal of Pediatrics, 155(3), 386-392.

Habre, W., Sims, C., \& D'Souza, M. (1997). Anaesthetic management of children with Joubert syndrome. Paediatric Anaesthesia, 7(3), 251-253.

Halbritter, J., Bizet, A. A., Schmidts, M., Porath, J. D., Braun, D. A., Gee, H. Y., ... Hildebrandt, F. (2013). Defects in the IFT-B component IFT172 cause Jeune and Mainzer-Saldino syndromes in humans. American Journal of Human Genetics, 93(5), 915-925.

Hannah, W. B., DeBrosse, S., Kinghorn, B., Strausbaugh, S., Aitken, M. L., Rosenfeld, M., ... Zariwala, M. A. (2019). The expanding phenotype of OFD1-related disorders: Hemizygous loss-of-function variants in 
three patients with primary ciliary dyskinesia. Molecular Genetics \& Genomic Medicine, 7(9), e911.

Hoefele, J., Wolf, M. T., O'Toole, J. F., Otto, E. A., Schultheiss, U., Deschenes, G., ... Hildebrandt, F. (2007). Evidence of oligogenic inheritance in nephronophthisis. Journal of the American Society of Nephrology, 18(10), 2789-2795.

Howie, L. D., Pastor, P. N., \& Lukacs, S. L. (2014). Use of medication prescribed for emotional or behavioral difficulties among children aged 6-17 years in the United States, 2011-2012. NCHS Data Brief, $148,1-8$

Huang, L., Szymanska, K., Jensen, V. L., Janecke, A. R., Innes, A. M., Davis, E. E., ... Boycott, K. M. (2011). TMEM237 is mutated in individuals with a Joubert syndrome related disorder and expands the role of the TMEM family at the ciliary transition zone. American Journal of Human Genetics, 89(6), 713-730.

Hynes, A. M., Giles, R. H., Srivastava, S., Eley, L., Whitehead, J., Danilenko, M., ... Sayer, J. A. (2014). Murine Joubert syndrome reveals Hedgehog signaling defects as a potential therapeutic target for nephronophthisis. Proceedings of the National Academy of Sciences of the United States of America, 111(27), 9893-9898.

Johnston, J. J., Lee, C., Wentzensen, I. M., Parisi, M. A., Crenshaw, M. M., Sapp, J. C., ... Biesecker, L. G. (2017). Compound heterozygous alterations in intraflagellar transport protein CLUAP1 in a child with a novel Joubert and oral-facial-digital overlap syndrome. Cold Spring Harbor Molecular Case Studies, 3(4). https://doi.org/10.1101/mcs.a001321.

Jonas, B. S., Gu, Q., \& Albertorio-Diaz, J. R. (2013). Psychotropic medication use among adolescents: United States, 2005-2010. NCHS Data Brief, 135, 1-8.

Joubert, M., Eisenring, J. J., Robb, J. P., \& Andermann, F. (1969). Familial agenesis of the cerebellar vermis. A syndrome of episodic hyperpnea, abnormal eye movements, ataxia, and retardation. Neurology, 19(9), 813-825.

Kamdar, B. B., Nandkumar, P., Krishnan, V., Gamaldo, C. E., \& Collop, N. A. (2011). Self-reported sleep and breathing disturbances in Joubert syndrome. Pediatric Neurology, 45(6), 395-399.

Karp, N., Grosse-Wortmann, L., \& Bowdin, S. (2012). Severe aortic stenosis, bicuspid aortic valve and atrial septal defect in a child with Joubert Syndrome and Related Disorders (JSRD)-A case report and review of congenital heart defects reported in the human ciliopathies. European Journal of Medical Genetics, 55(11), 605-610.

Katsanis, N., Ansley, S. J., Badano, J. L., Eichers, E. R., Lewis, R. A., Hoskins, B. E., ... Lupski, J. R. (2001). Triallelic inheritance in BardetBiedl syndrome, a Mendelian recessive disorder. Science, 293(5538), 2256-2259.

Khan, A. O., Oystreck, D. T., Seidahmed, M. Z., AlDrees, A., Elmalik, S. A., Alorainy, I. A., \& Salih, M. A. (2008). Ophthalmic features of Joubert syndrome. Ophthalmology, 115(12), 2286-2289.

Kim, Y. J., Kim, S., Jung, Y., Jung, E., Kwon, H. J., \& Kim, J. (2018). Eupatilin rescues ciliary transition zone defects to ameliorate ciliopathy-related phenotypes. The Journal of Clinical Investigation, 128(8), 3642-3648.

Kroes, H. Y., Fransen van de Putte, D. E., Ravesloot, C. J., \& Lindhout, D. (2007). The birth prevalence of Joubert syndrome: A population based study in the Netherlands. European Journal of Human Genetics, 15 (Suppl. 1). https://www.researchgate.net/publication/46694267_The birth_prevalence_of_Joubert_syndrome_a_population_based_study_in the_Netherlands

Kroes, H. Y., Van Zanten, B. G., De Ru, S. A., Boon, M., Mancini, G. M., Van der Knaap, M. S., ... Lindhout, D. (2010). Is hearing loss a feature of Joubert syndrome, a ciliopathy? International Journal of Pediatric Otorhinolaryngology, 74(9), 1034-1038.

Lambacher, N. J., Bruel, A. L., van Dam, T. J., Szymanska, K., Slaats, G. G., Kuhns, S., ... Blacque, O. E. (2016). TMEM107 recruits ciliopathy proteins to subdomains of the ciliary transition zone and causes Joubert syndrome. Nature Cell Biology, 18(1), 122-131.

Lee, J. E., Silhavy, J. L., Zaki, M. S., Schroth, J., Bielas, S. L., Marsh, S. E., ... Gleeson, J. G. (2012). CEP41 is mutated in Joubert syndrome and is required for tubulin glutamylation at the cilium. Nature Genetics, 44(2) 193-199.

Lee, J. H., Silhavy, J. L., Lee, J. E., Al-Gazali, L., Thomas, S., Davis, E. E., ... Gleeson, J. G. (2012). Evolutionarily assembled cis-regulatory module at a human ciliopathy locus. Science, 335(6071), 966-969.

Lehman, A. M., Eydoux, P., Doherty, D., Glass, I. A., Chitayat, D., Chung, B. Y., ... Trnka, P. (2010). Co-occurrence of Joubert syndrome and Jeune asphyxiating thoracic dystrophy. American Journal of Medical Genetics Part A, 152A(6), 1411-1419.

Levey, A. S., Stevens, L. A., Schmid, C. H., Zhang, Y. L., Castro, A. F., 3rd, Feldman, H. I., ... Coresh, J. (2009). A new equation to estimate glomerular filtration rate. Annals of Internal Medicine, 150(9), 604-612.

Maeder, M. L., Stefanidakis, M., Wilson, C. J., Baral, R., Barrera, L. A., Bounoutas, G. S., ... Jiang, H. (2019). Development of a gene-editing approach to restore vision loss in Leber congenital amaurosis type 10. Nature Medicine, 25(2), 229-233.

Malicdan, M. C., Vilboux, T., Stephen, J., Maglic, D., Mian, L., Konzman, D., ... Gunay-Aygun, M. (2015). Mutations in human homologue of chicken talpid3 gene (KIAA0586) cause a hybrid ciliopathy with overlapping features of Jeune and Joubert syndromes. Journal of Medical Genetics, 52(12), 830-839.

Maria, B. L., Boltshauser, E., Palmer, S. C., \& Tran, T. X. (1999). Clinical features and revised diagnostic criteria in Joubert syndrome. Journal of Child Neurology, 14(9), 583-590 discussion 590-581.

Maria, B. L., Hoang, K. B., Tusa, R. J., Mancuso, A. A., Hamed, L. M., Quisling, R. G., ... Frerking, B. (1997). "Joubert syndrome" revisited: Key ocular motor signs with magnetic resonance imaging correlation. Journal of Child Neurology, 12(7), 423-430.

Matthews, N. C. (1989). Anaesthesia in an infant with Joubert's syndrome. Anaesthesia, 44(11), 920-921.

Mercado, A., Pedraza, L., Mayol, P. M., Rodriguez Santana, R., \& Tejeda, C. (1991). Joubert syndrome. Respiratory failure requiring home mechanical ventilation. Boletin de la Asociacion Medica de Puerto Rico, 83(10), 451-455.

Mookherjee, S., Chen, H. Y., Isgrig, K., Yu, W., Hiriyanna, S., Levron, R., ... $\mathrm{Wu}, \mathrm{Z}$. (2018). A CEP290 C-terminal domain complements the mutant CEP290 of Rd16 mice in trans and rescues retinal degeneration. Cell Reports, 25(3), 611-623 e616.

Nuovo, S., Bacigalupo, I., Ginevrino, M., Battini, R., Bertini, E., Borgatti, R., ... Group JIS. (In press). Age and sex prevalence estimate of Joubert Syndrome in Italy. Neurology.

Nuovo, S., Fuiano, L., Micalizzi, A., Battini, R., Bertini, E., Borgatti, R., ... Emma, F. (2018). Impaired urinary concentration ability is a sensitive predictor of renal disease progression in Joubert syndrome. Nephrology Dialysis Transplantation. https://doi.org/10.1093/ndt/gfy333

Oka, M., Shimojima, K., Yamamoto, T., Hanaoka, Y., Sato, S., Yasuhara, T., ... Kobayashi, K. (2016). A novel HYLS1 homozygous mutation in living siblings with Joubert syndrome. Clinical Genetics, 89(6), 739-743.

Oster, M. E., Aucott, S. W., Glidewell, J., Hackell, J., Kochilas, L., Martin, G. R., ... Kemper, A. R. (2016). Lessons learned from newborn screening for critical congenital heart defects. Pediatrics, 137(5), e20154573.

Ozyurek, H., Kayacik, O. E., Gungor, O., \& Karagoz, F. (2008). Rare association of Hirschsprung's disease and Joubert syndrome. European Journal of Pediatrics, 167(4), 475-477.

Parisi M, Glass I. 1993. Joubert syndrome. In: Adam MP, Ardinger HH, Pagon RA, Wallace SE, Bean LJH, Stephens $K$, Amemiya $A$, GeneReviews((R)). Seattle, WA. https://www.ncbi.nlm.nih. gov/books/NBK1325/

Parisi, M. A., Bennett, C. L., Eckert, M. L., Dobyns, W. B., Gleeson, J. G., Shaw, D. W., ... Glass, I. A. (2004). The NPHP1 gene deletion associated with juvenile nephronophthisis is present in a subset of individuals with Joubert syndrome. American Journal of Human Genetics, 75 (1), 82-91. 
Parisi, M. A. \& Glass, I. A. (2003). Joubert syndrome. In: GeneReviews at GeneTests-GeneClinics: Medical Genetics Information Resource [database online]. Copyright, University of Washington, Seattle. Retrieved from http://wwwgeneclinicsorg or http:// wwwgenetestsorg.

Phelps, I. G., Dempsey, J. C., Grout, M. E., Isabella, C. R., Tully, H. M., Doherty, D., \& Bachmann-Gagescu, R. (2018). Interpreting the clinical significance of combined variants in multiple recessive disease genes: Systematic investigation of Joubert syndrome yields little support for oligogenicity. Genetics in medicine, 20(2), 223-233.

Platis, C. M., Kachko, L., Trabikin, E., Simhi, E., Bahar, M., \& Katz, J. (2006). Postoperative respiratory complications in Joubert syndrome. Paediatric Anaesthesia, 16(7), 799-800.

Poretti, A., Boltshauser, E., Loenneker, T., Valente, E. M., Brancati, F., Il'yasov, K., \& Huisman, T. A. (2007). Diffusion tensor imaging in Joubert syndrome. AJNR American Journal of Neuroradiology, 28(10), 1929-1933.

Poretti, A., Hausler, M., von Moers, A., Baumgartner, B., Zerres, K., Klein, A., ... Boltshauser, E. (2014). Ataxia, intellectual disability, and ocular apraxia with cerebellar cysts: A new disease? Cerebellum, 13(1), 79-88.

Poretti, A., Snow, J., Summers, A. C., Tekes, A., Huisman, T., Aygun, N., ... Gunay-Aygun, M. (2017). Joubert syndrome: Neuroimaging findings in 110 patients in correlation with cognitive function and genetic cause. Journal of Medical Genetics, 54(8), 521-529.

Poretti, A., Vitiello, G., Hennekam, R. C., Arrigoni, F., Bertini, E., Borgatti, R., ... Boltshauser, E. (2012). Delineation and diagnostic criteria of Oral-Facial-Digital Syndrome type VI. Orphanet Journal of Rare Diseases, 7, 4

Putoux, A., Thomas, S., Coene, K. L., Davis, E. E., Alanay, Y., Ogur, G., ... Attie-Bitach, T. (2011). KIF7 mutations cause fetal hydrolethalus and acrocallosal syndromes. Nature Genetics, 43(6), 601-606.

Ramsbottom, S. A., Molinari, E., Srivastava, S., Silberman, F., Henry, C., Alkanderi, S., ... Sayer, J. A. (2018). Targeted exon skipping of a CEP290 mutation rescues Joubert syndrome phenotypes in vitro and in a murine model. Proceedings of the National Academy of Sciences of the United States of America, 115(49), 12489-12494.

Reiter, J. F., \& Leroux, M. R. (2017). Genes and molecular pathways underpinning ciliopathies. Nature Reviews Molecular Cell Biology, 18(9), 533-547.

Romani, M., Micalizzi, A., Kraoua, I., Dotti, M. T., Cavallin, M., Sztriha, L., ... Valente, E. M. (2014). Mutations in B9D1 and MKS1 cause mild Joubert syndrome: Expanding the genetic overlap with the lethal ciliopathy Meckel syndrome. Orphanet Journal of Rare Diseases, 9, 72.

Romani, M., Micalizzi, A., \& Valente, E. M. (2013). Joubert syndrome: Congenital cerebellar ataxia with the molar tooth. The Lancet Neurology, 12(9), 894-905.

Roosing, S., Romani, M., Isrie, M., Rosti, R. O., Micalizzi, A., Musaev, D., ... Valente, E. M. (2016). Mutations in CEP120 cause Joubert syndrome as well as complex ciliopathy phenotypes. Journal of Medical Genetics, 53(9), 608-615.

Ruggenenti, P., Gentile, G., Perico, N., Perna, A., Barcella, L., Trillini, M., ... Remuzzi, G. (2016). Effect of sirolimus on disease progression in patients with autosomal dominant polycystic kidney disease and CKD stages 3b-4. Clinical Journal of the American Society of Nephrology, 11 (5), 785-794.

Russell, S., Bennett, J., Wellman, J. A., Chung, D. C., Yu, Z. F., Tillman, A., ... Maguire, A. M. (2017). Efficacy and safety of voretigene neparvovec (AAV2-hRPE65v2) in patients with RPE65-mediated inherited retinal dystrophy: A randomised, controlled, open-label, phase 3 trial. Lancet, 390(10097), 849-860.

Saleem, S. N., \& Zaki, M. S. (2010). Role of MR imaging in prenatal diagnosis of pregnancies at risk for Joubert syndrome and related cerebellar disorders. AJNR American journal of neuroradiology, 31(3), 424-429.
Sanders, A. A., de Vrieze, E., Alazami, A. M., Alzahrani, F., Malarkey, E. B., Sorusch, N., ... Blacque, O. E. (2015). KIAA0556 is a novel ciliary basal body component mutated in Joubert syndrome. Genome Biology, 16, 293.

Sang, L., Miller, J. J., Corbit, K. C., Giles, R. H., Brauer, M. J., Otto, E. A., ... Jackson, P. K. (2011). Mapping the NPHP-JBTS-MKS protein network reveals ciliopathy disease genes and pathways. Cell, 145(4), 513-528.

Sayer, J. A., Otto, E. A., O'Toole, J. F., Nurnberg, G., Kennedy, M. A., Becker, C., ... Hildebrandt, F. (2006). The centrosomal protein nephrocystin- 6 is mutated in Joubert syndrome and activates transcription factor ATF4. Nature Genetics, 38(6), 674-681.

Schwartz, G. J., Schneider, M. F., Maier, P. S., Moxey-Mims, M., Dharnidharka, V. R., Warady, B. A., ... Munoz, A. (2012). Improved equations estimating GFR in children with chronic kidney disease using an immunonephelometric determination of cystatin C. Kidney International, 82(4), 445-453.

Serra, A. L., Poster, D., Kistler, A. D., Krauer, F., Raina, S., Young, J., ... Wuthrich, R. P. (2010). Sirolimus and kidney growth in autosomal dominant polycystic kidney disease. The New England Journal of Medicine, 363(9), 820-829.

Shaheen, R., Jiang, N., Alzahrani, F., Ewida, N., Al-Sheddi, T., Alobeid, E., ... Alkuraya, F. S. (2019). Bi-allelic mutations in FAM149B1 cause abnormal primary cilium and a range of ciliopathy phenotypes in humans. American Journal of Human Genetics, 104(4), 731-737.

Shaheen, R., Schmidts, M., Faqeih, E., Hashem, A., Lausch, E., Holder, I., ... Alkuraya, F. S. (2015). A founder CEP120 mutation in Jeune asphyxiating thoracic dystrophy expands the role of centriolar proteins in skeletal ciliopathies. Human Molecular Genetics, 24(5), 1410-1419.

Shaheen, R., Shamseldin, H. E., Loucks, C. M., Seidahmed, M. Z., Ansari, S., Ibrahim Khalil, M., ... Alkuraya, F. S. (2014). Mutations in CSPP1, encoding a core centrosomal protein, cause a range of ciliopathy phenotypes in humans. American Journal of Human Genetics, 94(1), 73-79.

Shaheen, R., Szymanska, K., Basu, B., Patel, N., Ewida, N., Faqeih, E., ... Alkuraya, F. S. (2016). Characterizing the morbid genome of ciliopathies. Genome Biology, 17(1), 242.

Sriganesh, K., Smita, V., \& Aravind, H. S. (2010). Clonidine as a sole sedative agent for MRI study in a child with Joubert syndrome. Paediatric Anaesthesia, 20(6), 578-579.

Sriganesh, K., Vinay, B., Jena, S., Sudhir, V., Saini, J., \& Umamaheswara Rao, G. S. (2014). Anesthetic management of patients with Joubert syndrome: A retrospective analysis of a single-institutional case series. Paediatric Anaesthesia, 24(11), 1180-1184.

Srour, M., Hamdan, F. F., McKnight, D., Davis, E., Mandel, H., Schwartzentruber, J., ... Michaud, J. L. (2015). Joubert Syndrome in French Canadians and Identification of Mutations in CEP104. American Journal of Human Genetics, 97(5), 744-753.

Srour, M., Hamdan, F. F., Schwartzentruber, J. A., Patry, L., Ospina, L. H., Shevell, M. I., ... Michaud, J. L. (2012). Mutations in TMEM231 cause Joubert syndrome in French Canadians. Journal of Medical Genetics, 49(10), 636-641.

Srour, M., Schwartzentruber, J., Hamdan, F. F., Ospina, L. H., Patry, L., Labuda, D., ... Michaud, J. L. (2012). Mutations in C5ORF42 cause Joubert syndrome in the French Canadian population. American Journal of Human Genetics, 90(4), 693-700.

Stephen, J., Vilboux, T., Mian, L., Kuptanon, C., Sinclair, C. M., Yildirimli, D., ... Gunay-Aygun, M. (2017). Mutations in KIAA0753 cause Joubert syndrome associated with growth hormone deficiency. Human Genetics, 136(4), 399-408.

Stephen, L. A., Tawamie, H., Davis, G. M., Tebbe, L., Nurnberg, P., Nurnberg, G., ... Bolz, H. J. (2015). TALPID3 controls centrosome and cell polarity and the human ortholog KIAA0586 is mutated in Joubert syndrome (JBTS23). eLife, 4. https://doi.org/10.7554/eLife.08077

Strongin, A., Heller, T., Doherty, D., Glass, I. A., Parisi, M. A., Bryant, J., ... Gunay-Aygun, M. (2018). Characteristics of Liver Disease in 
100 Individuals With Joubert Syndrome Prospectively Evaluated at a Single Center. Journal of Pediatric Gastroenterology and Nutrition, 66(3), 428-435.

Sturm, V., Leiba, H., Menke, M. N., Valente, E. M., Poretti, A., Landau, K., \& Boltshauser, E. (2010). Ophthalmological Findings in Joubert Syndrome. Eye (London), 24(2), 222-225.

Summers, A. C., Snow, J., Wiggs, E., Liu, A. G., Toro, C., Poretti, A., ... Gunay-Aygun, M. (2017). Neuropsychological phenotypes of 76 individuals with Joubert syndrome evaluated at a single center. American Journal of Medical Genetics Part A, 173, 1796-1812.

Thauvin-Robinet, C., Lee, J. S., Lopez, E., Herranz-Perez, V., Shida, T., Franco, B., ... Nachury, M. V. (2014). The oral-facial-digital syndrome gene $\mathrm{C} 2 \mathrm{CD} 3$ encodes a positive regulator of centriole elongation. Nature Genetics, 46(8), 905-911.

Thomas, S., Legendre, M., Saunier, S., Bessieres, B., Alby, C., Bonniere, M., ... Attie-Bitach, T. (2012). TCTN3 mutations cause Mohr-Majewski syndrome. American Journal of Human Genetics, 91(2), 372-378.

Thomas, S., Wright, K. J., Le Corre, S., Micalizzi, A., Romani, M., Abhyankar, A., ... Attie-Bitach, T. (2014). A homozygous PDE6D mutation in Joubert syndrome impairs targeting of farnesylated INPP5E protein to the primary cilium. Human Mutation, 35(1), 137-146.

Toriyama, M., Lee, C., Taylor, S. P., Duran, I., Cohn, D. H., Bruel, A. L., ... Wallingford, J. B. (2016). The ciliopathy-associated CPLANE proteins direct basal body recruitment of intraflagellar transport machinery. Nature Genetics, 48(6), 648-656.

Tuz, K., Bachmann-Gagescu, R., O'Day, D. R., Hua, K., Isabella, C. R., Phelps, I. G., ... Ferland, R. J. (2014). Mutations in CSPP1 cause primary cilia abnormalities and Joubert syndrome with or without Jeune asphyxiating thoracic dystrophy. American Journal of Human Genetics, 94(1), 62-72.

Valente, E. M., Logan, C. V., Mougou-Zerelli, S., Lee, J. H., Silhavy, J. L., Brancati, F., ... Gleeson, J. G. (2010). Mutations in TMEM216 perturb ciliogenesis and cause Joubert, Meckel and related syndromes. Nature Genetics, 42(7), 619-625.

Valente, E. M., Silhavy, J. L., Brancati, F., Barrano, G., Krishnaswami, S. R., Castori, M., ... Gleeson, J. G. (2006). Mutations in CEP290, which encodes a centrosomal protein, cause pleiotropic forms of Joubert syndrome. Nature Genetics, 38(6), 623-625.

Van De Weghe, J. C., Rusterholz, T. D. S., Latour, B., Grout, M. E., Aldinger, K. A., Shaheen, R., ... Doherty, D. (2017). Mutations in ARMC9, which Encodes a Basal Body Protein, Cause Joubert Syndrome in Humans and Ciliopathy Phenotypes in Zebrafish. American Journal of Human Genetics, 101(1), 23-36.
Vilboux, T., Doherty, D. A., Glass, I. A., Parisi, M. A., Phelps, I. G., Cullinane, A. R., ... Gunay-Aygun, M. (2017). Molecular genetic findings and clinical correlations in 100 patients with Joubert syndrome and related disorders prospectively evaluated at a single center. Genetics in Medicine, 19(8), 875-882.

Vilboux, T., Malicdan, M. C., Roney, J. C., Cullinane, A. R., Stephen, J., Yildirimli, D., ... Gunay-Aygun, M. (2017). CELSR2, encoding a planar cell polarity protein, is a putative gene in Joubert syndrome with cortical heterotopia, microophthalmia, and growth hormone deficiency. American Journal of Medical Genetics Part A, 173(3), 661-666.

Vodopich, D. J., \& Gordon, G. J. (2004). Anesthetic management in Joubert syndrome. Paediatric Anaesthesia, 14(10), 871-873.

Walz, G., Budde, K., Mannaa, M., Nurnberger, J., Wanner, C., Sommerer, C., ... Eckardt, K. U. (2010). Everolimus in patients with autosomal dominant polycystic kidney disease. The New England Journal of Medicine, 363(9), 830-840.

Weiss, A. H., Doherty, D., Parisi, M., Shaw, D., Glass, I., \& Phillips, J. O. (2009). Eye movement abnormalities in Joubert syndrome. Investigative Ophthalmology \& Visual Science, 50(10), 4669-4677.

Wheway, G., Schmidts, M., Mans, D. A., Szymanska, K., Nguyen, T. T., Racher, H., ... Johnson, C. A. (2015). An siRNA-based functional genomics screen for the identification of regulators of ciliogenesis and ciliopathy genes. Nature Cell Biology, 17(8), 1074-1087.

Widjaja, E., Blaser, S., \& Raybaud, C. (2006). Diffusion tensor imaging of midline posterior fossa malformations. Pediatric Radiology, 36(6), 510-517.

Witmans, M., \& Young, R. (2011). Update on pediatric sleep-disordered breathing. Pediatric Clinics of North America, 58(3), 571-589.

Wolfe, L., Lakadamyali, H., \& Mutlu, G. M. (2010). Joubert syndrome associated with severe central sleep apnea. Journal of Clinical Sleep Medicine, 6(4), 384-388.

How to cite this article: Bachmann-Gagescu R, Dempsey JC, Bulgheroni S, et al. Healthcare recommendations for Joubert syndrome. Am J Med Genet Part A. 2019;1-21. https://doi. org/10.1002/ajmg.a.61399 